\title{
Comparative Genomics Provides Insight into the Function of Broad-Host Range Sponge Symbionts
}

\author{
(D) Samantha C. Waterworth, ${ }^{\mathrm{a}, \mathrm{b}}$ Shirley Parker-Nance, ${ }^{\mathrm{b}, \mathrm{c}}$ (D) Jason C. Kwan, ${ }^{\mathrm{a}}$ (D) Rosemary A. Dorrington ${ }^{\mathrm{b}, \mathrm{d}}$ \\ aDivision of Pharmaceutical Sciences, University of Wisconsin, Madison, Wisconsin, USA \\ bDepartment of Biochemistry and Microbiology, Rhodes University, Makhanda, South Africa \\ cSouth African Environmental Observation Network, Elwandle Coastal Node, Gqeberha (Port Elizabeth), South Africa \\ dSouth African Institute for Aquatic Biodiversity, Makhanda, South Africa
}

ABSTRACT The fossil record indicates that the earliest evidence of extant marine sponges (phylum Porifera) existed during the Cambrian explosion and that their symbiosis with microbes may have begun in their extinct ancestors during the Precambrian period. Many symbionts have adapted to their sponge host, where they perform specific, specialized functions. There are also widely distributed bacterial taxa such as Poribacteria, SAUL, and Tethybacterales that are found in a broad range of invertebrate hosts. Here, we added 11 new genomes to the Tethybacterales order, identified a novel family, and show that functional potential differs between the three Tethybacterales families. We compare the Tethybacterales with the well-characterized Entoporibacteria and show that these symbionts appear to preferentially associate with low-microbial abundance (LMA) and high-microbial abundance (HMA) sponges, respectively. Within these sponges, we show that these symbionts likely perform distinct functions and may have undergone multiple association events, rather than a single association event followed by coevolution.

IMPORTANCE Marine sponges often form symbiotic relationships with bacteria that fulfil a specific need within the sponge holobiont, and these symbionts are often conserved within a narrow range of related taxa. To date, there exist only three known bacterial taxa (Entoporibacteria, SAUL, and Tethybacterales) that are globally distributed and found in a broad range of sponge hosts, and little is known about the latter two. We show that the functional potential of broad-host range symbionts is conserved at a family level and that these symbionts have been acquired several times over evolutionary history. Finally, it appears that the Entoporibacteria are associated primarily with high-microbial abundance sponges, while the Tethybacterales associate with low-microbial abundance sponges.

KEYWORDS Latrunculiidae, Tethybacterales, Poribacteria, symbiosis, Porifera,

comparative genomics

W hile their exact time of origin is a subject of hot debate, fossil records indicate that extant marine sponges (phylum Porifera) existed during the Cambrian explosion, approximately 540 million years ago $(1,2)$, and that symbiotic relationships with microbes may have begun even before the evolution of extant sponge taxa (3). This would suggest that sponges may be one of the oldest living examples of symbiotic relationships. Sponges are remarkably efficient filter feeders, acquiring nutrients via phagocytosis of particulate matter, compromising mainly microbes, from the surrounding water (4). Since their emergence approximately 540 million years ago, sponges have evolved close associations with microbial symbionts that provide services essential for the fitness and survival of the host in diverse ecological niches (1, 5, 6). These symbionts are involved in a diverse array of beneficial processes, including

Citation Waterworth SC, Parker-Nance S, Kwan JC, Dorrington RA. 2021. Comparative genomics provides insight into the function of broad-host range sponge symbionts. $\mathrm{mBio} 12$ e01577-21. https://doi.org/10.1128/mBio .01577-21.

Editor Mark J. Bailey, CEH-Oxford

Copyright $\odot 2021$ Waterworth et al. This is an open-access article distributed under the terms of the Creative Commons Attribution 4.0 International license.

Address correspondence to Rosemary A. Dorrington, r.dorrington@ru.ac.za.

Received 7 June 2021

Accepted 13 August 2021

Published 14 September 2021 
the cycling of nutrients $(7,8)$ such as nitrogen $(8-13)$, sulfur $(14,15)$, and phosphate $(16,17)$, the acquisition of carbon $(18,19)$, and a supply of vitamins (20-23) and amino acids (20). They can play a role in the host sponge life cycle, such as promoting larval settlement (24). In addition, some symbionts provide chemical defenses against predators and biofouling through the production of bioactive compounds (25-28). In turn, the sponge host can provide symbionts with nutrients and minerals, such as creatinine and ammonia as observed in Cymbastela concentrica sponges (11).

As filter-feeders, sponges encounter large quantities of bacteria and other microbes. How sponges are able to distinguish between prey bacteria and those of potential benefit to the sponge, and the establishment of symbiotic relationships, is still not well understood, but the structure and composition of bacterial lipopolysaccharide, peptidoglycan, or flagellin may aid the host sponge in distinguishing symbionts from prey (29). Sponge hosts encode an abundance of nucleotide-binding domain and leucinerich repeat (NLR) receptors, which recognize different microbial ligands and potentially allow for distinction between symbionts, pathogens, and prey (30). Additionally, it has recently been shown that phages produce ankyrins which modulate the sponge immune response and allow for colonization by bacteria (31).

Symbionts are often specific to their sponge host with enriched populations relative to the surrounding seawater (32). However, there are a small number of "cosmopolitan" symbionts that are ubiquitously distributed across phylogenetically distant sponge hosts. The Poribacteria and "sponge-associated unclassified lineage" (SAUL) (33) are examples of such cosmopolitan bacterial species. Phylum Poribacteria bacteria were thought to be exclusively found in sponges (34). However, the identification of 13 putative Poribacteriarelated metagenome-assembled genomes (MAGs) from ocean water samples (35) led to the reclassification and distinction of sponge-associated Entoporibacteria and free-living Pelagiporibacteria within the phylum (36). Entoporibacteria are associated with phylogenetically divergent sponge hosts in distant geographic locations, with no apparent correlations between their phylogeny and that of their sponge host or location $(36,37)$. Different Poribacteria phylotypes have been detected within the same sponge species (38). The Entoporibacteria carry several genes $(39,40)$ that encode enzymes responsible for the degradation of carbohydrates and metabolism of sulfates and uronic acid (41-43), prompting the hypothesis that these bacteria may be involved in the breakdown of the proteoglycan host matrix (43). However, subsequent analyses of Poribacteria transcriptomes from the mesohyl of Aplysina aerophoba sponges showed that genes involved in carbohydrate metabolism were not highly expressed (42). Instead, there was a higher expression of genes involved in 1,2-propanediol degradation and import of vitamin $B_{12}$, which together suggest that the bacterium may import vitamin $B_{12}$ as a necessary cofactor for anaerobic 1,2-propanediol degradation and energy generation (42).

The SAUL bacteria belong to the larger taxon of candidate phylum PAUC34f and have been detected, although at low abundance, in several sponge species (44). Hostassociated SAUL bacteria were likely acquired by eukaryotic hosts (sponges, corals, tunicates) at different evolutionary time points and are phylogenetically distinct from their planktonic relatives (44). Previous investigations into the only two SAUL bacterial genomes provided evidence to suggest that these symbionts may play a role in the degradation of host and algal carbohydrates, as well as the storage of phosphate for the host during periods of phosphate limitation (33).

Recently, a third group of ubiquitous sponge-associated betaproteobacterial symbionts were described (45). The proposed new order, the Tethybacterales, comprises two families, the Tethybacteraceae and the Persebacteraceae (45). Based on assessment of MAGs representative of different species within these two families, it was shown that the bacteria within these families had functionally radiated, as they coevolve with their specific sponge host (45). The Tethybacterales are distributed both globally and with phylogenetically diverse sponges that represent both high-microbial abundance (HMA) and low-microbial abundance (LMA) sponges (45). These bacteria have also been detected in other marine invertebrates, ocean water samples, and marine sediment (45), 
suggesting that these symbionts may have, at one point, been acquired from the surrounding environment.

Tethybacterales are conserved in several sponge microbiomes (46) and can be the numerically dominant bacterial population $(15,47-54)$, with some predicted to be endosymbiotic (15, 47, 52). In Amphimedon queenslandica, the AqS2 symbiont, Amphirhobacter heronislandensis (family Tethybacteraceae), is codominant with sulfur-oxidizing Gammaproteobacteria AqS1. A. heronislandensis AqS2, is present in all stages of the sponge life cycle (55) and appears to have a reduced genome (15). Interestingly, the AqS2 MAG shares some functional similarity with the codominant AqS1, including the potential to generate energy via carbon monoxide oxidation, assimilate sulfur, and produce most essential amino acids (15). However, these sympatric symbionts differ significantly in what metabolites they could possibly transport (15).

In this study, we used the dominant, conserved Tethybacterales (strain Sp02-1) symbiont of Tsitsikamma (subgenus Tsitsikamma) favus sponge species (family Latrunculiidae) (56-60) as a springboard into a deeper investigation of Tethybacterales. Here, we report a comparative study using new and existing Tethybacterales genomes and show that functional potential follows that of their taxonomic ranking rather than host-specific adaptation. We also show that the Tethybacterales and Poribacteria have distinct functional repertoires, that these bacterial families can coexist in a single host, and that the Tethybacterales may represent a more ancient lineage of ubiquitous sponge-associated symbionts.

\section{RESULTS AND DISCUSSION}

The microbiomes of sponges of the Latrunculiidae family are highly conserved and are dominated by populations of related betaproteobacterial symbionts. These bacteria have since been reclassified as class Gammaproteobacteria, as several betaproteobacteria were, when genome phylogeny was proposed as the basis for taxonomy, which has since been incorporated in the Genome Taxonomy Database (GTDB) (61). The numerically dominant symbiont in $T$. (T.) favus sponges is strain Sp02-1. Based on their 16S rRNA gene sequence, the Sp02-1 strain and closely related symbionts from different latrunculid sponges are likely members of the newly described Tethybacterales order.

Characterization of the putative Tethybacterales genome bin. Genome bin 003B_4, from sponge specimen TIC2018-003B, included a 16S rRNA gene sequence that shared 99.86\% identity with the T. (T.) favus-associated Tethybacterales Sp02-1 (previously called the betaproteobacterium Sp02-1 [56, 57]) full-length 16S rRNA gene clone (GenBank accession number HQ241787.1). The next-closest relatives were uncultured 16S clones from Xestospongia muta and Tethya aurantium sponges (Fig. S2). Bins 050A_14, 050C_6, and 003D_6 were also identified as possible representatives of Tethybacterales Sp02-1 based on their predicted phylogenetic relatedness. However, they were of low quality and were not used in downstream analyses.

Genome bin 003B_4 was used as a representative of the Tethybacterales Sp02-1 symbiont. Bin 003B_4 is approximately $2.95 \mathrm{Mbp}$ in size and of medium quality per MIMAG standards (62) (Table S1), and it has a notable abundance of pseudogenes ( $\sim 25 \%$ of all genes), which resulted in a coding density of $65.27 \%$, far lower than the average for bacteria (63). An abundance of pseudogenes and low coding density are usually indications that the genome in question may be undergoing genome reduction (64), similar to other genomes in the proposed order of Tethybacterales (45).

The Tethybacterales Sp02-1 genome carries all genes necessary for glycolysis and PRPP biosynthesis, and most genes required for the citrate cycle and oxidative phosphorylation were detected in the gene annotations. Also present are the genes necessary to biosynthesize valine, leucine, isoleucine, tryptophan, phenylalanine, tyrosine, and ornithine amino acids, as well as genes required for transport of L-amino acids, proline, and branched amino acids. This would suggest that this bacterium may exchange amino acids with the host, as observed previously in both insect and sponge-associated symbioses $(11,65,66)$. 
A total of 13 genes unique to the Tethybacterales Sp02-1 symbiont were identified (i.e., not identified elsewhere in the $T$. [T.] favus metagenomes). One gene was predicted to encode an $A B C$ transporter permease subunit that was likely involved in glycine betaine and proline betaine uptake. A second gene encoded 5-oxoprolinase subunit PxpA (Table S5). The presence of these two genes suggests that the Tethybacterales Sp02-1 genome can acquire proline and convert it to glutamate (67) in addition to glutamate already produced via glutamate synthase. Other unique genes encode a restriction endonuclease subunit and site-specific DNA-methyltransferase, which would presumably aid in defense against foreign DNA. At least seven of the unique gene products are predicted to be associated with phages, including the antirestriction protein ArdA. ArdA is a protein that has previously been shown to mimic the structures of DNA normally bound by type I restriction modification enzymes, which prevent DNA cleavage, and effectively results in antirestriction activity (68). If functionally active in the Tethybacterales Sp02-1 symbiont, we speculate that this protein may similarly prevent DNA cleavage through its mimicry of the targeted DNA structures and protect the genome against type I restriction modification enzymes. Finally, two of the unique genes were predicted to encode an ankyrin repeat domain-containing protein and a von Willebrand factor type A (VWA) domain-containing protein. These two proteins are known to be involved in cell-adhesion and protein-protein interactions $(69,70)$, and if active within the symbiont, they may help facilitate the symbiosis between the Tethybacterales Sp02-1 symbiont and the sponge host.

Comparison of putative Sp02-1 with other Tethybacterales. Several Tethybacterales sponge symbionts have been described to date, and these bacteria are thought to have functionally diversified following the initiation of their ancient partnership (45). To test this hypothesis, we downloaded 12 genomes/MAGs of Tethybacterales (classified as AqS2 in GTDB) from the JGI database. Additionally, we assembled and binned metagenomic data from 36 sponge SRA data sets, covering 14 sponge species, and recovered an additional 14 AqS2-like genomes. Of the total 27 bins, 10 were of low quality, so Bin 003B_4 (Sp02-1) and 16 medium-quality Tethybacterales bins/genomes were used for further analysis (Table 1).

First, the phylogeny of the Tethybacterales symbionts was determined using singlecopy marker genes in autoMLST, revealing a deep branching clade of these spongeassociated symbionts and revealing that bin 003B_4 clustered within the proposed Persebacteraceae family (Fig. 1). All members of the Persebacteraceae family dominate the microbial community of their respective sponge hosts $(47,56,57,71)$. We additionally identified what appears to be a third family, consisting of symbionts associated with Coelocarteria singaporensis and Cinachyrella sponge species (Fig. 1). Assessment of shared average amino acid identity (AAI) indicates that these genomes represent a new family, sharing an average of $80 \%$ AAI within the family (Table S6) (72). These three families share less than $89 \%$ sequence similarity with respect to their $16 \mathrm{~S}$ rRNA sequences, with intraclade differences of less than $92 \%$ (Table S6). Therefore, they may represent novel classes (72) within the Tethybacterales order. While it is still hotly debated whether MAGs should be named at the genus level (73-76), we chose to tentatively name the additional genera and family after Oceanids of Greek mythology in keeping with Taylor and colleagues, who initially resolved the Tethybacterales order (45). We propose the family name Polydorabacteraceae, which means "many gifts." Additionally, we propose species names for the newly identified genera as follows: Bin 003B_4 is a single representative of "Candidatus Ukwabelana africanus," Bin Imet_M1_9 and Bin ImetM2_1_1 are both representatives of "Candidatus Regalo mexicanus," Bin CCyA_2_3 and CCyB_3_2 are both representatives of "Candidatus Dora taiwanensis," and all six bins from $C$. singaporensis are representative of "Candidatus Hadiah malacca." In each case, the genus name means "gift from" in the local language (where possible) from where the host sponge was collected, and the species name reflects the region/country from which the sponge host was collected.

We identified 4,306 groups of orthologous genes between all 17 Tethybacterales genomes, with only 18 genes common to all the genomes. More shared genes were 


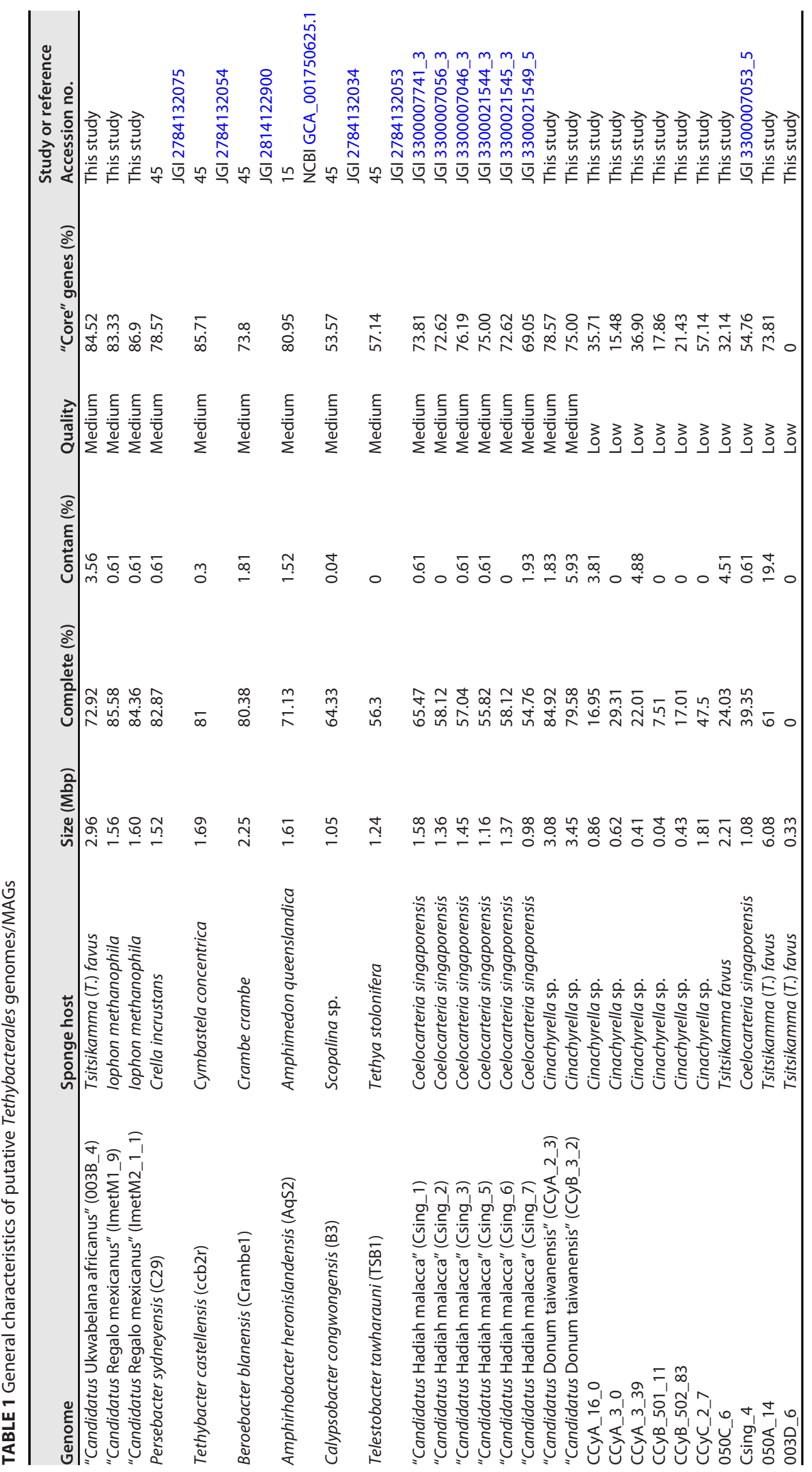




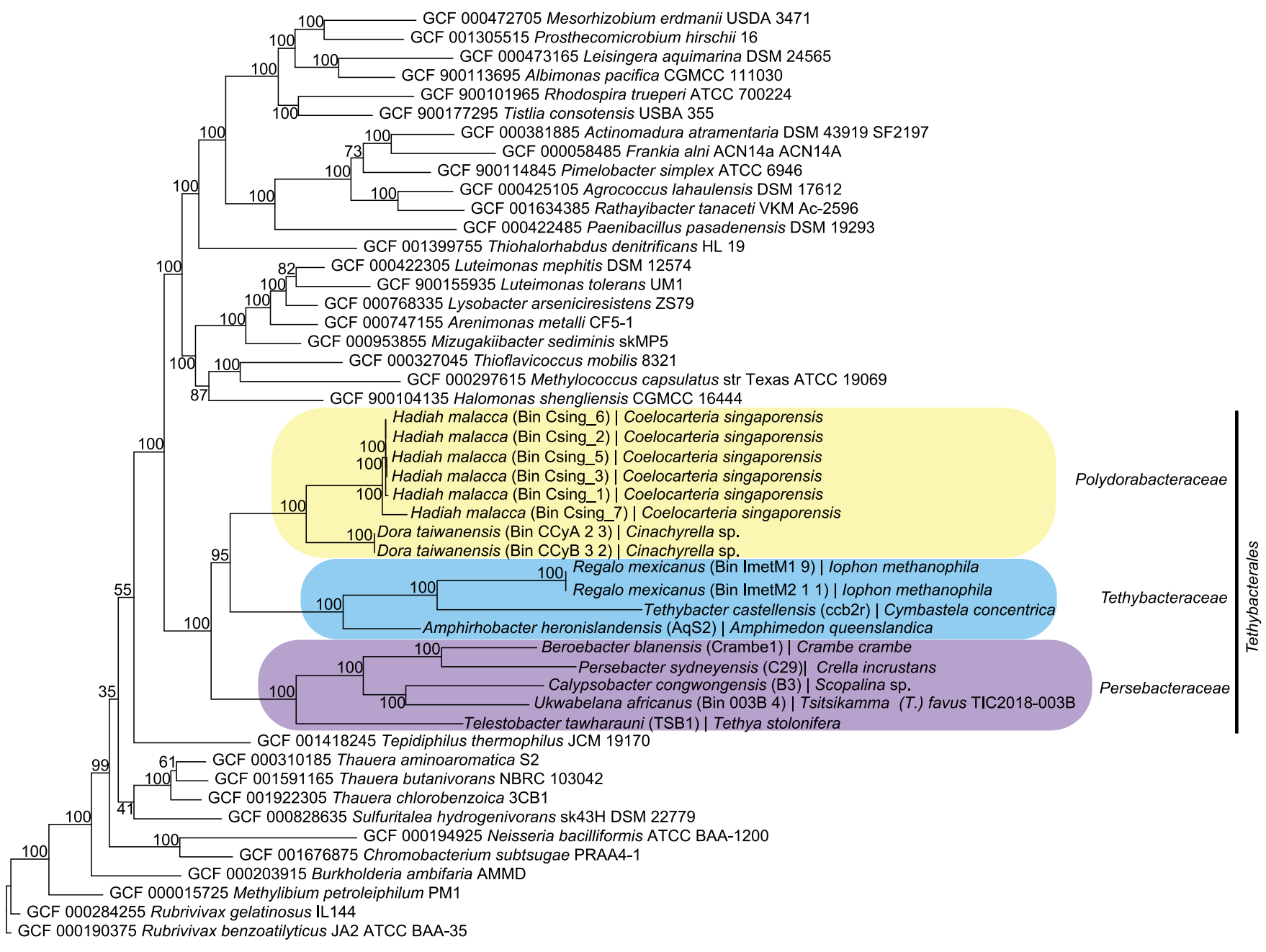

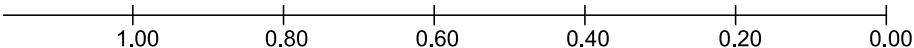

FIG 1 Phylogeny of the Tethybacterales sponge symbionts. Using autoMLST, single-copy markers were selected and used to delineate the phylogeny of these sponge-associated betaproteobacteria, revealing a new family of symbionts in the Tethybacterales order. Additionally, it was shown that the $T$. ( $T$.) favus-associated Sp02-1 symbiont belongs to the Persebacteraceae family. The phylogenetic tree was inferred using the de novo method in AutoMLST using a concatenated alignment with IQ Tree and ModelFinder enabled. Branch lengths are proportional to the number of substitutions per site.

expected, but as several of the genomes investigated are incomplete, it is possible that additional common genes would be found if the genomes were complete. Hierarchical clustering of gene presence/absence data revealed that the gene pattern of Bin 003B_4 most closely resembled that of Tethybacterales genomes from Crambe crambe, Crella incrustans, and the Scopalina sp. sponges (family Persebacteraceae) (Fig. 2A). A total of 13 of the shared genes between all Tethybacterales genomes encoded ribosomal proteins or those involved in energy production. Genes encoding chorismate synthase were found across all 17 genomes and suggest that tryptophan production may be shared among these bacteria. According to a recent study, Dysidea etheria and A. queenslandica sponges cannot produce tryptophan (a possible essential amino acid), which may indicate a common role for the Tethybacterales symbionts as tryptophan producers (77). Several other shared genes were predicted to encode proteins involved in stress responses, including protein-methionine-sulfoxide reductase, ATP-dependent Clp protease, and chaperonin enzyme proteins, which aid in protein folding or degradation under various stressors (78-82). Internal changes in oxygen levels (83) and temperature changes (84-86) are examples of stressors experienced by the sponge holobiont. It is unsurprising that this clade of largely sponge-specific Tethybacterales share the ability to deal with these many stressors as they adapt to their fluctuating environment. 
A.

A. Hadiah malacca (Bin Csing_5) | Coelocarteria singaporensis

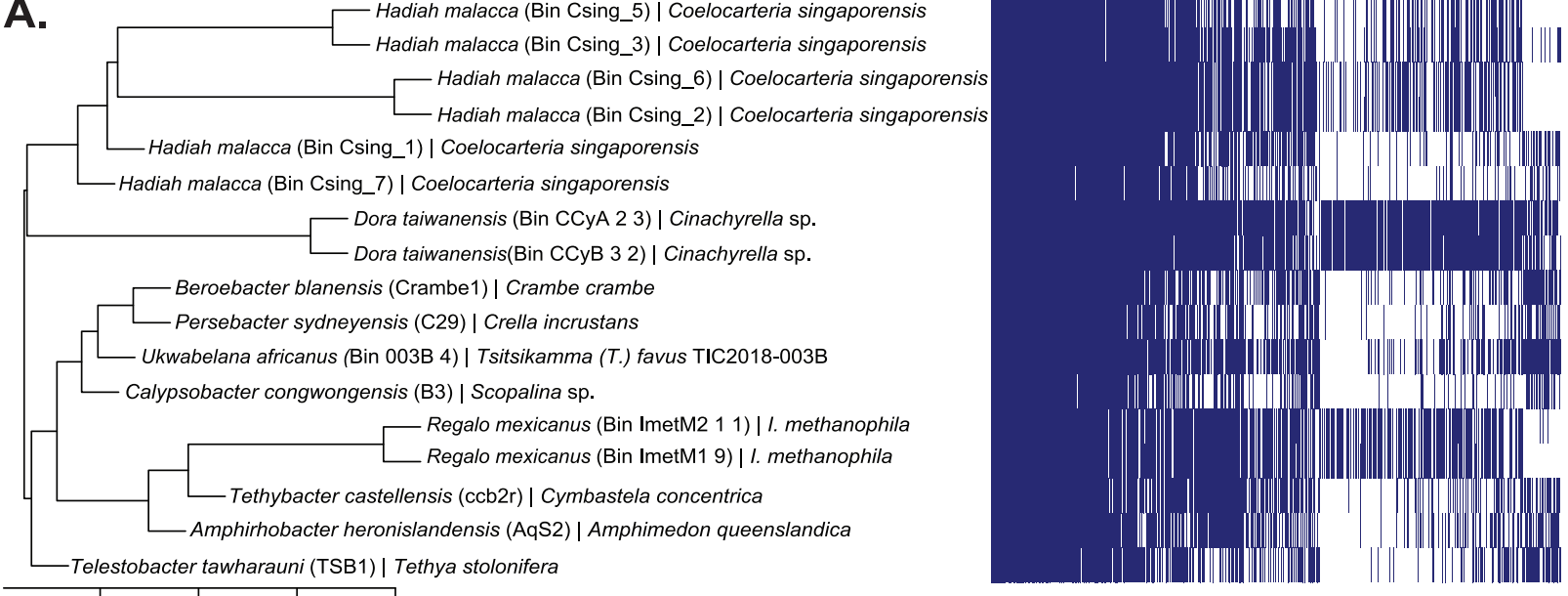

$\begin{array}{llll}0.6 & 0.4 & 0.2 & 0.0\end{array}$

\section{B. $\square$ Polydorabacteraceae \\ Tethybacteraceae \\ Persebacteraceae}

Hadiah malacca (Bin Csing_6) I Coelocarteria singaporensis Hadiah malacca (Bin Csing_2) | Coelocarteria singaporensis Hadiah malacca (Bin Csing_5) | Coelocarteria singaporensis Hadiah malacca (Bin Csing_3) | Coelocarteria singaporensis Hadiah malacca (Bin Csing_1) | Coelocarteria singaporensis Hadiah malacca (Bin Csing_7) | Coelocarteria singaporensis Dora taiwanensis (Bin CCyA 2 3) | Cinachyrella sp. Dora taiwanensis (Bin ССyB 3 2) | Cinachyrella sp. Regalo mexicanus (Bin ImetM1 9) | I. methanophila Regalo mexicanus (Bin ImetM2 1 1) | I. methanophila Tethybacter castellensis (ccb2r) | Cymbastela concentrica Amphirhobacter heronislandensis (AqS2) | Amphimedon queenslandica Beroebacter blanensis (Crambe1) | Crambe crambe Persebacter sydneyensis (C29) | Crella incrustans Calypsobacter congwongensis (B3) | Scopalina sp. (Bin 003B 4) | Tsitsikamma (T.) favus TIC2018-003B Telestobacter tawharauni (TSB1) | Tethya stolonifera
Assim. S :

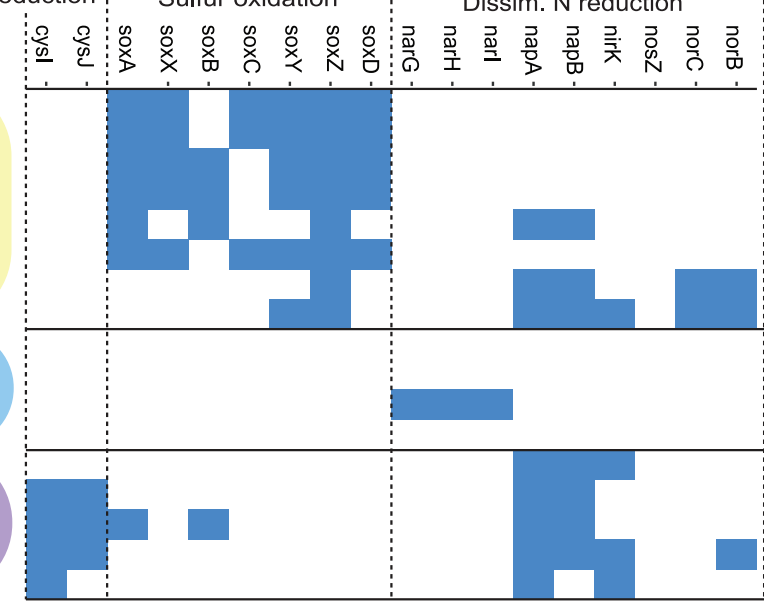

C. Polydorabacteraceae
Tethybacteraceae
Persebacteraceae

Gene count

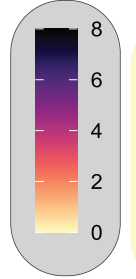

Hadiah malacca (Bin Csing_6) | Coelocarteria singaporensis Hadiah malacca (Bin Csing_2) | Coelocarteria singaporensis Hadiah malacca (Bin Csing 5) | Coelocarteria singaporensis Hadiah malacca (Bin Csing_3) | Coelocarteria singaporensis Hadiah malacca (Bin Csing_1) | Coelocarteria singaporensis Hadiah malacca (Bin Csing_7) | Coelocarteria singaporensis Dora taiwanensis (Bin CCyA 23 ) | Cinachyrella sp. Dora taiwanensis (Bin CCyB 3 2) | Cinachyrella sp. Regalo mexicanus (Bin ImetM1 9) | I. methanophila Regalo mexicanus(Bin ImetM2 1 1) | I. methanophila Tethybacter castellensis (ccb2r) | Cymbastela concentrica Amphirhobacter heronislandensis (AqS2) | Amphimedon queenslandica Beroebacter blanensis (Crambe1) | Crambe crambe Persebacter sydneyensis (C29) | Crella incrustans Calypsobacter congwongensis (B3) | Scopalina sp. Ukwabelana africanus (Bin 003B 4) | Tsitsikamma (T.) favus TIC2018-003B Telestobacter tawharauni (TSB1) | Tethya stolonifera

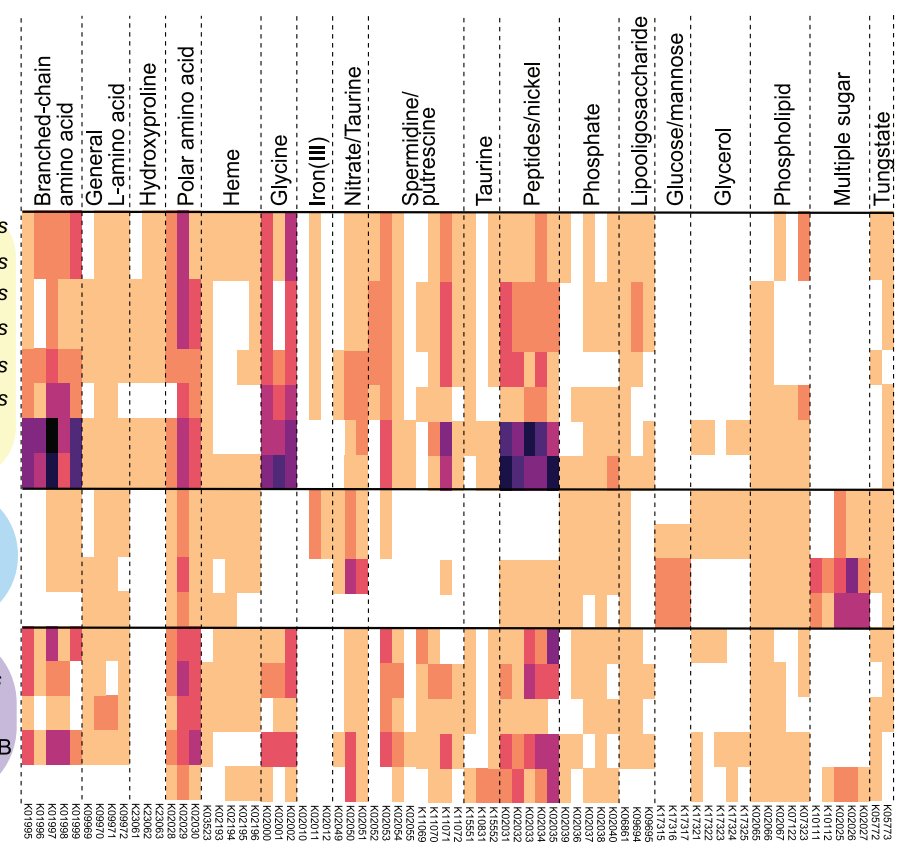

FIG 2 Functional specialization of Tethybacterales families. The newly proposed Tethybacterales order appears to consist of three bacterial families. (A to C) These families appear to have similar gene distribution (A), where the potential function of these genes indicates specialization in nutrient cycling (B) and solute transport (C). 
Alignment against the KEGG database revealed some noteworthy trends that differentiated the three Tethybacterales families (Fig. 2B; Table S7): (i) the genomes of the proposed Polydorabacteraceae family include several genes associated with sulfur oxidation; (ii) the Persebacteraceae are unique in their potential for reduction of sulfite $(c y s / J)$, and (iii) the Tethybacteraceae have the potential for cytoplasmic nitrate reduction (narGHI), while the other two families may perform denitrification. Similarly, the families differ to some extent in what can be transported in and out of the symbiont cell (Fig. 2C). Proposed members of the Polydorabacteraceae appear exclusively capable of transporting hydroxyproline, which may imply a role in collagen degradation (87). The Tethybacteraceae and Persebacteraceae appear able to transport spermidine, putrescine, taurine, and glycine, which in combination with their potential to reduce nitrates, may suggest a role in $\mathrm{C}-\mathrm{N}$ cycling (88). All three families transport various amino acids as well as phospholipids and heme. The exchange of amino acids between symbiont and sponge host has previously been observed (89) and may provide the Tethybacterales with a competitive advantage over other sympatric microorganisms (90) and possibly allow the sponge hosts to regulate the symbioses via regulation of the quantity of amino acids available for symbiont uptake (91). Similarly, the transfer of heme in the iron-starved ocean environment between sponge host and symbiont could provide a selective advantage, as heme may act as a supply of iron (92). The Tethybacteraceae were distinct from the other two families in their potential to transport sugars. As mentioned earlier, the transport of sugars plays an important role in symbiotic interactions $(84,93-95)$, and it is possible that this family of symbionts require sugars from their sponge hosts.

Comparative analyses of functional potential between Tethybacterales and Poribacteria. We wanted to determine whether broad-host range sponge-associated symbionts have converged to perform similar roles in their sponge hosts. Accordingly, we annotated 62 Poribacteria genomes, which consisted of 24 Pelagiporibacteria (free-living) and 38 Entoporibacteria (sponge-associated) genomes, and the 17 Tethybacterales genomes against the KEGG database. We catalogued the presence/absence of 896 unique genes spanning carbohydrate metabolism, methane metabolism, nitrogen metabolism, sulfur metabolism, phosphate metabolism, and several transporter systems (Table S7). Inspection of the functional potential in the Tethybacterales and Poribacteria revealed several insights (Fig. 3). The gene repertoires of the Poribacteria and the Tethybacterales are distinct from one another (Fig. S3; Table 2), with notable differences, including the genes associated with dissimilatory nitrate reduction, thiosulfate oxidation, and transport of glycine betaine/proline, glycerol, taurine, tungstate, and lipooligosaccharides, all of which are present in at least two of the three Tethybacterales families and absent in the Poribacteria (Fig. 3). Conversely, several gene clusters were detected in the Poribacteria and absent in the Tethybacterales, including trehalose biosynthesis, galactose degradation, phosphate metabolism, assimilatory sulfate reduction, and transport of phosphonate, urea, iron complexes, molybdate, and hydroxymethylpyrimidine (Fig. 3). It has been reported that both Entoporibacteria and Pelagiporibacteria include genes associated with denitrification (36); however, we could not detect many genes associated with nitrogen metabolism in our analyses (Fig. 3).

We cross-checked gene annotations generated using Prokka (HAMAP database) and BLAST (nonredundant [nr] database). Genes associated with assimilatory nitrate reduction (narB and nirA) were identified in Poribacteria using these alternate annotations, but we could not detect genes associated with denitrification in the Poribacteria. Conversely, genes associated with denitrification (napAB and nirk) were detected in the Persebacteraceae of the Tethybacterales in Prokka, BLAST, and KEGG annotations (Fig. 3), indicating that their absence in Poribacteria genomes was not an artifact of our analyses.

Pairwise analysis of similarity (ANOSIM) (using Bray-Curtis distance) confirmed that the functional genetic repertoire (KEGG annotations) of the Tethybacterales bacteria showed a strong, significant dissimilarity to that of the sponge-associated Entoporibacteria and the free-living Pelagiporibacteria (Table 2). In addition, the Polydorabacteraceae and the 
Entoporibacteria Pelagiporibacteria

Tethybacteraceae

Polydorabacteraceae

Persebacteraceae

Entner-Doudoroff pathway

Galactose degradation

Trehalose biosynthesis

Denitrification

Dissimilatory nitrate reduction

Phosphate metabolism

Assimilatory sulfate reduction

SOX complex

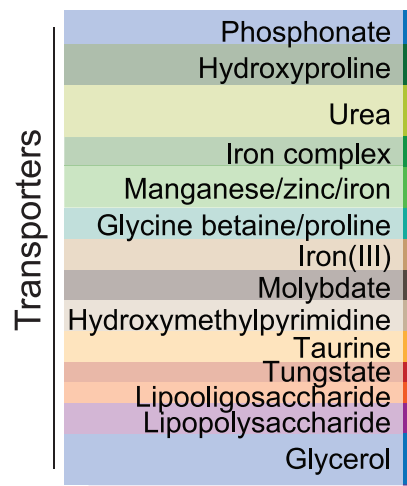

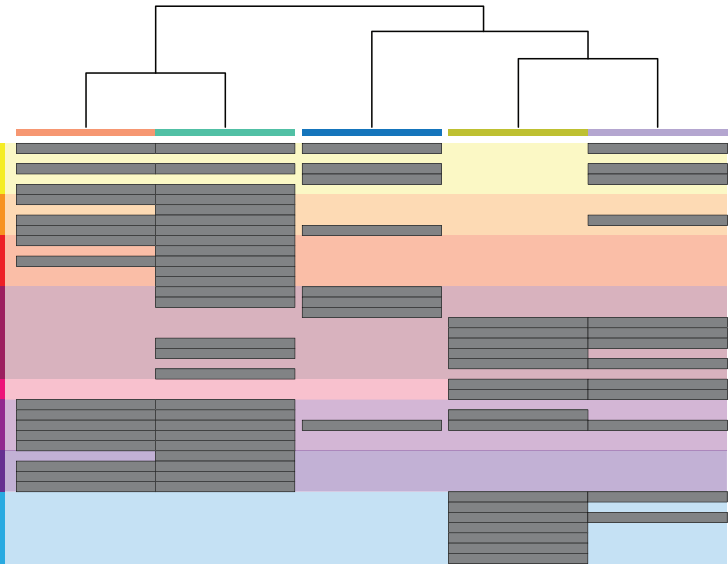

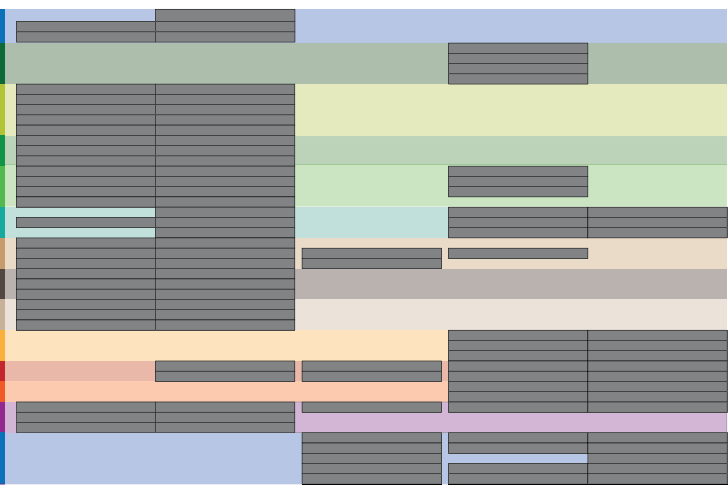

FIG 3 Notable functional differences between Tethybacterales and Poribacteria. A summary of the most significant differences in the functional gene repertoires of bacterial families with the Poribacteria and Tethybacterales. The presence of metabolic genes (KEGG annotations) detected in any Tethybacterales and Poribacteria genome bins is indicated with a gray block.

Persebacteraceae were significantly different from one another, but the lower R statistic would suggest that the dissimilarity is not as strong as that between other groups in this analysis, while the Tethybacteraceae appear to be more functionally distinct from the other two Tethybacterales families.

Taken together, these data suggest that the three Tethybacterales families and the Entoporibacteria lineages may each fulfil distinct functional or ecological niches within a given sponge host. We then considered the sponge hosts themselves and found that Entoporibacteria included in this study associate exclusively with high-microbial abundance (HMA) sponges, while the Tethybacterales largely associate with low-microbial abundance (LMA) sponges (Table 3). This difference is consistent with previous findings that LMA and HMA sponges have different bacterial community structures, where the HMA sponges are associated with highly abundant, highly diverse, and similar bacterial

TABLE 2 Pairwise ANOSIM of presence/absence of KEGG-annotated functional genes in Poribacteria and Tethybacterales

\begin{tabular}{llll}
\hline Taxonomy A & Taxonomy B & P value & $R$ statistic \\
\hline Entoporibacteria & Kalypsobacteraceae & 0.0001 & 0.9819 \\
Entoporibacteria & Pelagiporibacteria & 0.0001 & 0.5248 \\
Entoporibacteria & Persebacteraceae & 0.0001 & 0.9929 \\
Entoporibacteria & Tethybacteraceae & 0.0001 & 0.9581 \\
Kalypsobacteraceae & Pelagiporibacteria & 0.0007 & 0.4909 \\
Kalypsobacteraceae & Persebacteraceae & 0.0015 & 0.4776 \\
Kalypsobacteraceae & Tethybacteraceae & 0.0033 & 0.8915 \\
Pelagiporibacteria & Persebacteraceae & 0.0033 & 0.5301 \\
Pelagiporibacteria & Tethybacteraceae & 0.0663 & 0.3124 \\
Persebacteraceae & Tethybacteraceae & 0.0082 & 0.5938 \\
\hline
\end{tabular}


communities across all sponges, and LMA sponges have fewer bacterial cells, with lower diversity and often a dominant single population (96-98). More specifically, Poribacteria have been identified as "indicator species" for HMA sponges, and Betaproteobacteria (now within the Gammaproteobacteria class) were indicator species of LMA sponges (97, 99). However, exceptions to Tethybacterales associating exclusively with LMA sponges were observed. First, the lophon methanophila sponges which harbor symbionts within the Tethybacteraceae family do not conform to the LMA/HMA dichotomy (100), and second, some sponges, such as C. singaporensis (HMA), can play host to both Tethybacterales and Entoporibacteria species (Table 3), which provides further evidence that these symbionts may serve different purposes within their sponge host. However, why and how these different sponge types select for different broad-host range symbionts remain to be discovered.

We investigated the respective approximate divergence pattern of the Tethybacterales and the Entoporibacteria and whether their divergence followed that of their sponge hosts. The 18 homologous genes shared between the Tethybacterales were used to estimate the rate of synonymous substitution, which provides an approximation for the pattern of divergence between the species (101). We found that the estimated divergence pattern of the Tethybacterales (Fig. 4A) and the phylogeny of the host sponges (Fig. 4B) was incongruent. Phylogenetic trees inferred using single-copy marker genes (Fig. 1) and the comprehensive $16 \mathrm{~S}$ rRNA tree published by Taylor and colleagues (45) confirm this lack of congruency between symbiont and host phylogeny. Other factors, such as collection site or depth, could not explain the observed trend. Similar incongruence of symbiont and host phylogeny was observed for the Entoporibacteria (34 homologous genes used to estimate synonymous substitution rates) (Fig. $4 C$ and D), in agreement with previous phylogenetic studies $(34,36,37)$. This would suggest that these sponges likely acquired a free-living Tethybacterales common ancestor at different time points throughout their evolution and that the same is true for the Entoporibacteria. Evidence of coevolution of betaproteobacteria symbionts within sponge families $(49,55,56,102)$ implies that Tethybacterales symbionts were likely acquired horizontally at various time points and may have coevolved with their respective hosts subsequent to acquisition.

Finally, the estimated rates of synonymous substitution of homologous genes were used to estimate the relative times at which the Tethybacterales and Entoporibacteria taxa began diverging. Regardless of the substitution rate used, it was found that the sponge-associated Tethybacterales genomes began diverging from one another before the Entoporibacteria began diverging from one another (Table S4). If one accepts that divergence between exclusively sponge-associated bacterial lineages began when the common ancestor first associated with a sponge host, then the earlier divergence of sponge-associated Tethybacterales (relative to the Entoporibacteria) suggests that the Tethybacterales may have associated with sponges before the Poribacteria common ancestor and represent a more ancient symbiont. However, this hypothesis may prove false if additional Entoporibacteria lineages are discovered and added to the analyses, or other factors such as mutation rates, time between symbiont acquisition, and transition to vertical inheritance of symbionts or fossil records disprove this hypothesis.

Conclusion. Here, we have shown that the family to which a broad-host range symbiont belongs dictates the functional potential of the symbiont. This work has expanded our understanding of the Tethybacterales and the possible functional specialization of the families within this new order. The Tethybacterales are functionally distinct from the Poribacteria, which would suggest that although these bacteria are both ubiquitously associated with a wide range of sponge hosts, they likely have not converged to fulfil the same role. Instead, it would appear that these symbionts were selected by the various sponge hosts for existing functional capabilities that fulfil requirements of either HMA or LMA sponges. The phylogenetic incongruence of both Tethybacterales and Entoporibacteria and their respective sponge hosts suggests that their ancestors were horizontally acquired at different evolutionary time points, and coevolution may have occurred following the establishment of the association. Estimates of when the Tethybacterales and Entoporibacteria began diverging from their respective common ancestors implied that Tethybacterales may have associated with a 


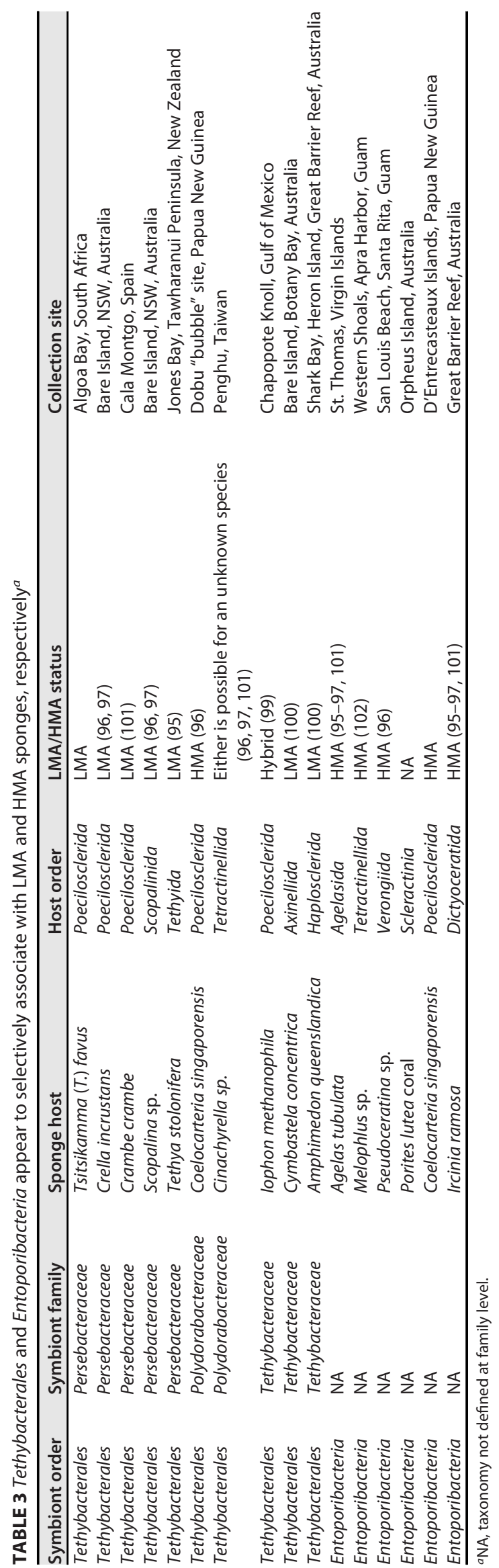



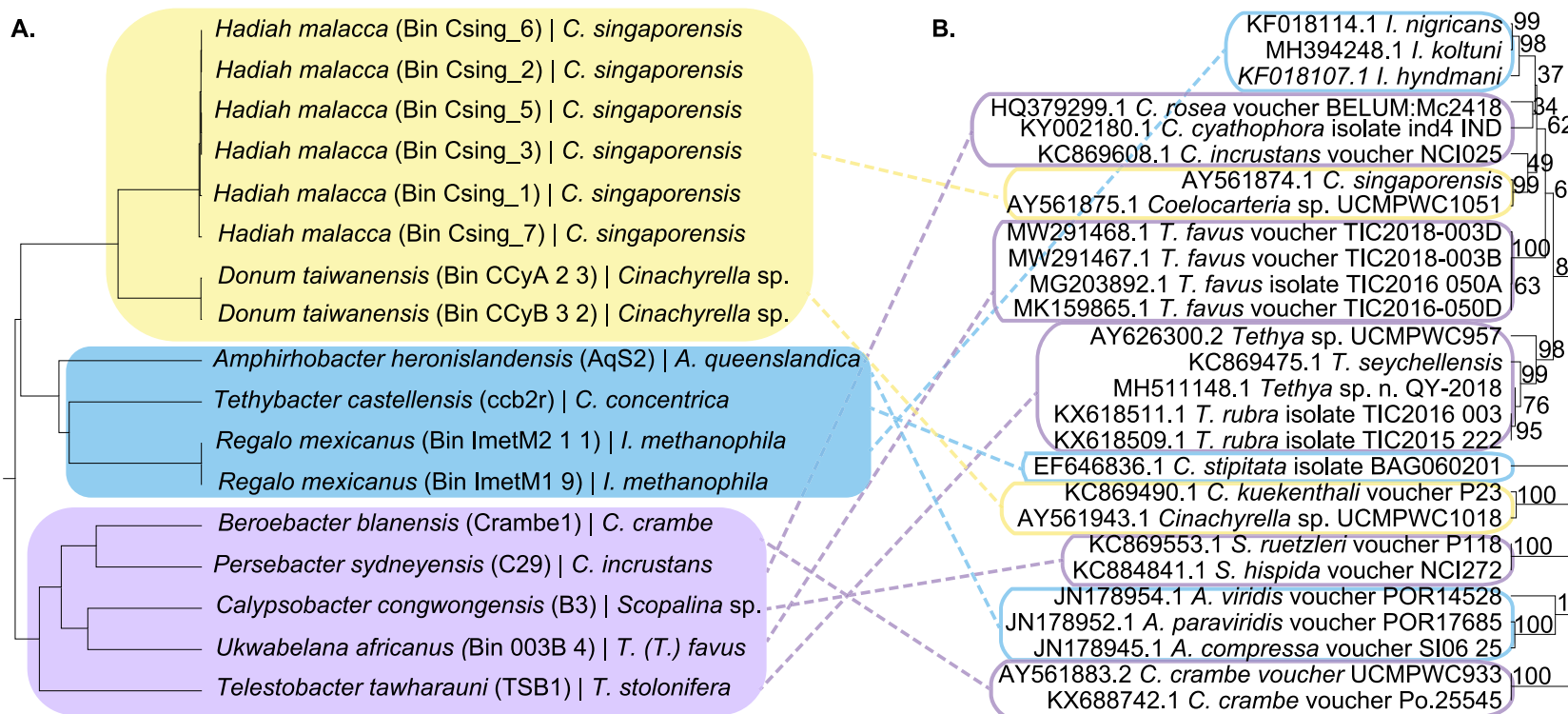

KY002180 . rosea voucher BELUM:Mc2418 $\rightarrow 34$ KY002180.1 C. cyathophora isolate ind4 IND
KC869608.1 C. incrustans voucher NCl025 AY561874.1 C. singaporensis 9996 AY561875.1 Coelocarteria sp. UCMPWC1051 MW291468.1 T. favus voucher TIC2018-003D MW291467.1 T. favus voucher TIC2018-003B 100 , MG203892.1 T favus isolate TIC2016 050A 63 MK159865.1 T favus voucher TIC2016-050D AY626300.2 Tethya sp. UCMPWC957 $\square 98$ KC869475.1 T. seychellensis 798 MH511148.1 Tethya sp. n. QY-2018 KX618511.1 T. rubra isolate TIC2016 003 KX618509.1 T. rubra isolate TIC2015 222

EF646836.1 C stipitata isolate BAG060201 KC869490.1 C. kuekenthali voucher P23 100 AY561943.1 Cinachyrella sp. UCMPWC1018 KC869553.1 S. ruetzleri voucher P118 100 KC884841.1 S. hispida voucher NCl272 JN178954.1 A. viridis voucher POR14528 $\square 100$

JN178952.1 A. paraviridis voucher POR17685 100 JN178945.1 A. compressa voucher SI06 25

AY561883.2 C. crambe voucher UCMPWC933 100 KX688742.1 C. crambe voucher Po.25545

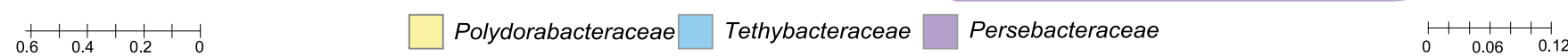

C.

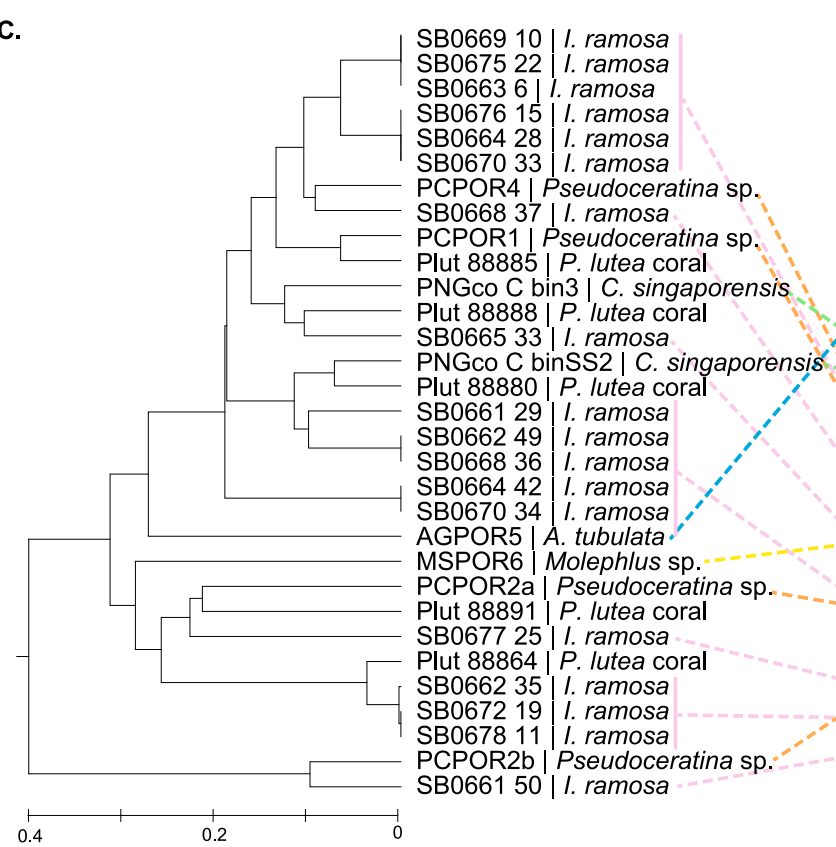
SB0669 10 | I. ramosa SB0675 22 | I. ramosa SB0676 $15 \mid$ I. ramosa SB0664 28 I. ramosa SB0670 33 | I. ramosa PCPOR4 | Pseudoceratina sp. SB0668 37 | I. ramosa Plut 88885 seudoceratina s PNGco C bin3 | C singaporensis Plut $88888 \mid P$. lutea coral SB0665 33 | I. ramosa PNGco $\mathrm{C}$ binSS2 | C. singaporensis Plut $88880 \mid P$. lutea cora I. ramosa SB0662 49 I. ramosa SB0668 36 I. ramosa SB0664 42 I. ramosa AGPOR5 I A tubulata. MSPOR6 | Molephlus sp PCPOR2a | Pseudoceratina sp Plut $88891 \mid P$. Iutea cora SB0677 25 | I. ramosa SB0662 35 . Iutea coral SB0672 19 I. ramosa SB0678 11 I. ramosa SB066150| I. ramosa

Persebacteraceae

D. AY561929.2 Agelas sp. UCMPWC1026 KX688750.1 A. oroides voucher Po.25569 . 100

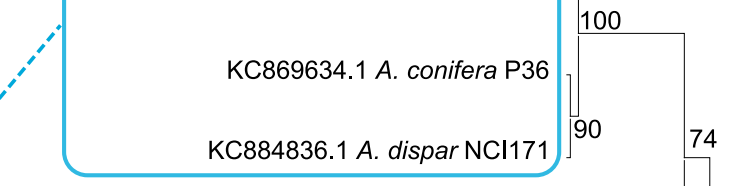

AY561940.1 Melophlus sp. UCMPWC1052

KC869514.1 Pseudoceratina arabica NCI317

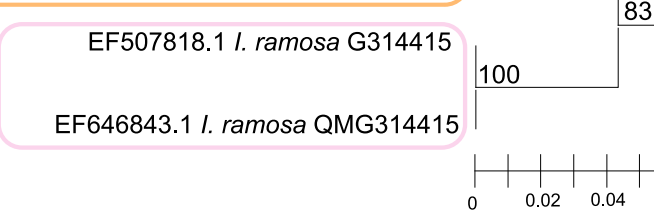

FIG 4 The divergence pattern of sponge-associated Tethybacterales, Entoporibacteria, and their respective host sponges. The divergence of the Tethybacterales and Entoporibacteria is incongruent with the phylogeny of the host sponges. (A and C) The branch length of symbiont divergence estimates is proportional to the pairwise rate of synonymous substitution calculated (ML estimation) using a concatenation of genes common to all genomes. The rate of synonymous substitution was calculated using PAL2NAL and CodeML from the PAML package and visualized in MEGA X. (B and D) The phylogeny of host sponges (or close relatives thereof) was inferred with 28S rRNA sequence data using the UPGMA method and maximum composite likelihood model with 1,000 bootstrap replicates. Branch lengths indicate the number of substitutions per site. All ambiguous positions were removed for each sequence pair (pairwise deletion option). Evolutionary analyses were conducted in MEGA X.

sponge host before the Entoporibacteria, and therefore the Tethybacterales may be an older sponge-associated symbiont. However, additional data are required to validate or disprove this hypothesis.

\section{MATERIALS AND METHODS}

Sponge collection and taxonomic identification. Sponge specimens Tsitsikamma (Tsitsikamma) favus TIC2016-050A and TIC2016-050C were collected in June 2016 at Evans Peak (33.84548 S, $25.31663^{\circ} \mathrm{E}$ ) at a depth of $20 \mathrm{~m}$ via self-contained underwater breathing apparatus (SCUBA). Sponge 
specimens T. (T.) favus TIC2018-003B and TIC2018-003D were collected in March 2018 at Evans Peak $\left(33.84213^{\circ} \mathrm{S}, 25.81655^{\circ} \mathrm{E}\right)$ at a depth of $25 \mathrm{~m}$ via SCUBA. Collection permits were acquired prior to collection from the Department Environmental Affairs (DEA) and the Department of Environment, Forestry, and Fisheries (DEFF) under the following permit numbers: in 2015, RES2015/16 and RES2015/21; in 2016, RES2016/11; in 2017, RES2017/43; and in 2018, RES2018/44. Sponge specimens were stored on ice during collection and, thereafter, at $-20^{\circ} \mathrm{C}$. Subsamples collected for DNA extraction were preserved in RNALater (Invitrogen) and stored at $-20^{\circ} \mathrm{C}$. Sponge specimens were dissected, thin sections were generated, and spicules were mounted on microscope slides and examined to allow species identification, as done previously (103-105). Molecular barcoding (28S rRNA gene) was also performed for several of the sponge specimens (Fig. S1) as described previously (56).

Metagenomic sequencing and analysis. Small sections of each preserved sponge (approximately $2 \mathrm{~cm}^{3}$ ) were pulverized in $2 \mathrm{ml}$ sterile artificial seawater $\left(24.6 \mathrm{~g} \mathrm{NaCl}, 0.67 \mathrm{~g} \mathrm{KCl}, 1.36 \mathrm{~g} \mathrm{CaCl}_{2} \cdot 2 \mathrm{H}_{2} \mathrm{O}, 6.29\right.$ $\mathrm{g} \mathrm{MgSO}_{4} \cdot 7 \mathrm{H}_{2} \mathrm{O}, 4.66 \mathrm{~g} \mathrm{MgCl}_{2} \cdot 6 \mathrm{H}_{2} \mathrm{O}, 0.18 \mathrm{~g} \mathrm{NaHCO}_{3}$, and distilled $\mathrm{H}_{2} \mathrm{O}$ to 1 liter) with a sterile mortar and pestle. The resultant homogenate was centrifuged at $16,000 \mathrm{rpm}$ for $1 \mathrm{~min}$ to pellet cellular material. Genomic DNA (gDNA) was extracted using the ZR fungal/bacterial DNA miniprep kit (D6005; Zymo Research). Shotgun metagenomic sequencing was performed for four $T$. (T.) favus sponge specimens using lon Torrent platforms. Shotgun metagenomic libraries, of reads $200 \mathrm{bp}$ in length, were prepared for each of the four sponge samples (TIC2016-050A, TIC2018-003B, TIC2016-050C, and TIC2018-003D) using an lon P1.1.17 chip. Additional sequence data of 400 bp were generated for TIC2016-050A using an Ion S5 530 chip. TIC2016-050A served as a pilot experiment, and we wanted to identify which read length was best for our investigations. However, we did not want to waste additional sequence data and included it when assembling the TIC2016-050A metagenomic contigs, so the 400-bp reads were included in the assembly of these metagenomes. Metagenomic data sets were assembled into contiguous sequences (contigs) with SPAdes v3.12.0 (106) using the -iontorrent and -only-assembler options. Contigs that were classified as bacterial were selected and clustered into genomic bins using Autometa (107) and manually curated for optimal completion and purity. Validation of the bins was performed using CheckM v1.0.12 (108). Of the 50 recovered genome bins, 5 were of high quality, 13 were of medium quality, and 32 were of low quality in accordance with MIMAG standards (62) (Table S1).

Acquisition and assembly of reference genomes. The genome of $A$. queenslandica symbiont Aqs2 (GCA_001750625.1) was retrieved from the NCBI database. Similarly, other sponge-associated Tethybacterales MAGs from the JGl database were downloaded and used as references (3300007741_3, 3300007056_3, 3300007046_3, 3300007053_5, 3300021544_3, 3300021545_3, 3300021549_5, 2784132075, 2784132054, 2814122900, 2784132034, and 2784132053).

A total of 36 raw-read SRA data sets from sponge metagenomes were downloaded from the SRA database (Table S2). Illumina reads from these data sets were trimmed using Trimmomatic v0.39 (109) and assembled using SPAdes v3.14 (106) in -meta mode. Contigs classified as bacterial were selected and used for further binning using Autometa (107). This resulted in a total of 393 additional genome bins (Table S1), the quality of which was assessed using CheckM (108) and taxonomically classified with GTDB-Tk (110) with database release 95. A total of 27 bins were classified as AqS2 and were considered likely members of the newly proposed Tethybacterales order (45). However, 10 of the 27 bins were low quality and were not used in downstream analyses. In addition, 59 Poribacteria genome bins were downloaded from the NCBI database for functional comparison (Table S3), and three were used from the 393 genome bins generated in this study (Geodia parva sponge hosts).

Taxonomic identification. Partial and full-length 16S rRNA gene sequences were extracted from bins using barrnap 0.9 (https://github.com/tseemann/barrnap). Extracted sequences were aligned against the $\mathrm{nr}$ database using BLASTn (111). Genomes were additionally uploaded individually to autoMLST (112) and analyzed in both placement mode and de novo mode (IQ tree and ModelFinder options enabled and concatenated gene tree selected). All bins and downloaded genomes were taxonomically identified using GTDB-Tk (110).

Genome annotation and metabolic potential analysis. All bins and downloaded genomes were annotated using Prokka v1.13 (113) with NCBI compliance enabled. Protein-coding amino-acid sequences from genomic bins were annotated against the KEGG database using kofamscan (114) with output in mapper format. Custom Python scripts were used to summarize annotation counts (find scripts here: https://github.com/samche42/Family_matters). Potential biosynthetic gene clusters (BGCs) were identified by uploading genome bins to the antiSMASH Web server (115) with all options enabled. Predicted amino acid sequences of genes within each identified gene cluster were aligned against the $\mathrm{nr}$ database using BLASTp (111) to identify the closest homologs. Protein sequences of genes within each identified gene cluster were aligned against the nr database using BLASTp (111) to identify the closest homolog.

Phylogeny and function of Tethybacterales species. A subset of orthologous genes common to all medium-quality Tethybacterales genomes/bins was created. Shared amino acid identity (AAl) was calculated with the aai.rb script from the enveomics package (116). 16S rRNA genes were analyzed using BLASTn (111). Functional genes were annotated against the KEGG database using kofamscan (114). Annotations were collected into functional categories and visualized in R (see https://github.com/ samche42/Family_matters for all scripts). A Nonmetric multidimensional scaling (NMDS) plot of the presence/absence metabolic counts was constructed using Bray-Curtis distance using the vegan package (117) in R. Analysis of similarity (ANOSIM) analyses were also conducted using the vegan package in R using Bray-Curtis distance and 9,999 permutations.

Genome divergence estimates. Divergence estimates were performed as described previously (118). Briefly, homologous genes in Tethybacterales genomes were identified using OMA v2.4.2 (119). A subset of homologous genes present in all genomes was created. Homologous genes were aligned using MUSCLE 
v3.8.155 (120) and clustered into fasta files representing each genome using merge_fastas_for_dNdS.py (see https://github.com/samche42/Family_matters for all scripts). The corresponding nucleotide sequences were extracted from Prokka annotations using multifasta_seqretriever.py. All stop codons were removed using remove_stop_codons.py. All nucleotide sequences, per genome, were concatenated to produce a single nucleotide sequence per genome using the union function from EMBOSS (121). All amino acid sequences were similarly concatenated. This resulted in a single concatenated nucleotide sequence and a single concatenated amino acid sequence per genome. Concatenated nucleotide sequences were clustered into two fasta files (one nucleotide, one protein sequence) and then aligned using PAL2NAL (122). The resultant alignment was then run in codeml to produce pairwise synonymous substitution rates (dS). Divergence estimates can be determined by dividing pairwise dS values by a given substitution rate (substitutions per year) and be further divided by 1 million to provide estimates of branch divergence million years ago (mya). Pairwise synonymous substitution rates can be found in Table S4. Pairwise divergence values were illustrated as a tree using MEGA X (123). Concatenated amino acid and nucleotide sequences of the 18 orthologous genes were aligned using MUSCLE v3.8.155 (120), and the evolutionary history was inferred using the UPMGA method (124) in MEGA X (123) with 10,000 bootstrap replicates.

Identification of unique and host-associated genes in putative symbiont genome bins. A custom database of genes from all bacterial bins (with the exception of the putative Tethybacterales symbionts) was created using the "makedb" option in DIAMOND (125) to identify genes that were unique to the putative Tethybacterales symbionts. To be exhaustive and screen against the entire metagenome, genes from low-quality genomes (except low-quality putative Tethybacterales genomes), small contigs $(<3000 \mathrm{bp}$ ) that were not included in binning, and unclustered contigs (i.e., included in binning but not placed within a bin) were included in this database. Putative Tethybacterales genes were aligned using DIAMOND blast (125). A gene was considered "unique" if the aligned hit shared less than $40 \%$ amino acid identity with any other genes from the $T$. (T.) favus metagenomes and had no significant hits against the $\mathrm{nr}$ database or were identified as pseudogenes. All "unique" putative Tethybacterales genes annotated as "hypothetical" (both Prokka and NCBI nr database annotations) were removed. Finally, we compared Prokka annotation strings between the putative Tethybacterales bins and all other T. (T.) favus-associated genome bins and excluded any putative Tethybacterales genes that were found to have the same annotation as a gene in one of the other bins.

Data availability. The raw $16 \mathrm{~S}$ amplicon and metagenomic read data can be accessed from the NCBI website under BioProject PRJNA508092.

\section{SUPPLEMENTAL MATERIAL}

Supplemental material is available online only.

FIG S1, EPS file, 1.1 MB.

FIG S2, EPS file, 0.6 MB.

FIG S3, EPS file, 1.3 MB.

TABLE S1, TXT file, 0.1 MB.

TABLE S2, TXT file, $0.002 \mathrm{MB}$.

TABLE S3, TXT file, $0.02 \mathrm{MB}$.

TABLE S4, TXT file, $0.02 \mathrm{MB}$.

TABLE S5, TXT file, $0.002 \mathrm{MB}$.

TABLE S6, TXT file, $0.005 \mathrm{MB}$.

TABLE S7, TXT file, $0.3 \mathrm{MB}$.

\section{ACKNOWLEDGMENTS}

This research was performed in part using the computer resources and assistance of the UW-Madison Center for High Throughput Computing in the Department of Computer Sciences. The CHTC is supported by UW-Madison, the Advanced Computing Initiative, the Wisconsin Alumni Research Foundation, Wisconsin Institutes for Discovery, and the National Science Foundation and is an active member of the Open Science Grid, which is supported by the National Science Foundation and the U.S. Department of Energy's Office of Science.

We also acknowledge the South African Center for High-Performance Computing for providing computing facilities for bioinformatics data analysis. we acknowledge Gwynneth Matcher (The South African Institute for Aquatic Biodiversity, Aquatic Genomics Research Platform) and Carel van Heerden and Alvera Vorster (Stellenbosch University Central Analytical Facility) for their next-generation sequencing (NGS) technical support. We thank Ryan Palmer and Koos Smith (ACEP) for technical support and expertise during sponge collections. We thank the South African Environmental Observation Network, Elwandle Coastal Node, and the Shallow Marine and Coastal 
Research Infrastructure for the use of their research platforms and infrastructure and South African National Parks for their assistance and support.

We declare no competing interests, financial or otherwise, in relation to the work described here.

This research was funded by grants from the South African National Research Foundation (NRF) to R.A.D., including the South Africa Research Chair Initiative (SARChI) grant (UID: 87583), the African Coelacanth Ecosystem Programme (ACEP) (UID: 97967), and the SARChl-led Communities of Practice Programme (UID: 110612). S.C.W. was supported by an NRF Innovation and Rhodes University Henderson Ph.D. scholarships. S.P.-N. holds an NRF PDP scholarship (grant number 101038). The opinions expressed and conclusions arrived at are those of the authors and are not necessarily to be attributed to any of the above-mentioned donors.

\section{REFERENCES}

1. Botting JP, Nettersheim BJ. 2018. Searching for sponge origins. Nat Ecol Evol 2:1685-1686. https://doi.org/10.1038/s41559-018-0702-4.

2. Botting JP, Muir LA. 2018. Early sponge evolution: a review and phylogenetic framework. Palaeoworld 27:1-29. https://doi.org/10.1016/j.palwor 2017.07.001.

3. Uriz MJ, Agell G, Blanquer A, Turon X, Casamayor EO. 2012. Endosymbiotic calcifying bacteria: a new cue to the origin of calcification in metazoa? Evolution 66:2993-2999. https://doi.org/10.1111/j.1558-5646.2012 $.01676 . x$.

4. Taylor MW, Radax R, Steger D, Wagner M. 2007. Sponge-associated microorganisms: evolution, ecology, and biotechnological potential. Microbiol Mol Biol Rev 71:295-347. https://doi.org/10.1128/MMBR.00040-06.

5. Webster NS, Taylor MW. 2012. Marine sponges and their microbial symbionts: love and other relationships. Environ Microbiol 14:335-346. https://doi.org/10.1111/j.1462-2920.2011.02460.x.

6. Wilkinson CR, Smith DC. 1984. Immunological evidence for the Precambrian origin of bacterial symbioses in marine sponges. Proc R Soc Lond B Biol Sci 220:509-518.

7. Zhang F, Jonas L, Lin H, Hill RT. 2019. Microbially mediated nutrient cycles in marine sponges. FEMS Microbiol Ecol 95:fiz155. https://doi.org/ 10.1093/femsec/fiz155.

8. Karimi E, Slaby BM, Soares AR, Blom J, Hentschel U, Costa R. 2018. Metagenomic binning reveals versatile nutrient cycling and distinct adaptive features in alphaproteobacterial symbionts of marine sponges. FEMS Microbiol Ecol 94:fiy074. https://doi.org/10.1093/femsec/fiy074.

9. Hoffmann F, Radax R, Woebken D, Holtappels M, Lavik G, Rapp HT, Schläppy M-L, Schleper C, Kuypers MMM. 2009. Complex nitrogen cycling in the sponge Geodia barretti. Environ Microbiol 11:2228-2243. https://doi.org/10.1111/j.1462-2920.2009.01944.x.

10. Bayer K, Schmitt S, Hentschel U. 2007. Microbial nitrification in Mediterranean sponges: possible involvement of ammonia-oxidizing, 165-171. In Custodio MR (ed), Porifera Research Biodiversity Innovation \& Sustainability. Universidade Federal do Rio de Janeiro, Rio de Janeiro, Brazil.

11. Moitinho-Silva L, Díez-Vives C, Batani G, Esteves Al, Jahn MT, Thomas T. 2017. Integrated metabolism in sponge-microbe symbiosis revealed by genome-centered metatranscriptomics. ISME J 11:1651-1666. https:// doi.org/10.1038/ismej.2017.25.

12. Bayer K, Schmitt S, Hentschel U. 2008. Physiology, phylogeny and in situ evidence for bacterial and archaeal nitrifiers in the marine sponge Aplysina aerophoba. Environ Microbiol 10:2942-2955. https://doi.org/10 .1111/j.1462-2920.2008.01582.x.

13. Chaib De Mares $M$, Jiménez DJ, Palladino $G$, Gutleben J, Lebrun LA, Muller EEL, Wilmes P, Sipkema D, van Elsas JD. 2018. Expressed protein profile of a Tectomicrobium and other microbial symbionts in the marine sponge Aplysina aerophoba as evidenced by metaproteomics. Sci Rep 8: 11795. https://doi.org/10.1038/s41598-018-30134-0.

14. Jensen S, Fortunato SAV, Hoffmann F, Hoem S, Rapp HT, Øvreås L, Torsvik VL. 2017. The relative abundance and transcriptional activity of marine sponge-associated microorganisms emphasizing groups involved in sulfur cycle. Microb Ecol 73:668-676. https://doi.org/10.1007/s00248-016-0836-3.

15. Gauthier M-EA, Watson JR, Degnan SM. 2016. Draft genomes shed light on the dual bacterial symbiosis that dominates the microbiome of the coral reef sponge Amphimedon queenslandica. Front Mar Sci 3:196. https://doi.org/10.3389/fmars.2016.00196.
16. Zhang F, Blasiak LC, Karolin JO, Powell RJ, Geddes CD, Hill RT. 2015. Phosphorus sequestration in the form of polyphosphate by microbial symbionts in marine sponges. Proc Natl Acad Sci U S A 112:4381-4386. https://doi.org/10.1073/pnas.1423768112.

17. Colman AS. 2015. Sponge symbionts and the marine P cycle. Proc Natl Acad Sci U S A 112:4191-4192. https://doi.org/10.1073/pnas.1502763112.

18. Wilkinson CR. 1983. Net primary productivity in coral reef sponges. Science 219:410-412. https://doi.org/10.1126/science.219.4583.410.

19. Feng G, Li Z. 2019. Carbon and nitrogen metabolism of sponge microbiome, p 145-169. In Li Z (ed), Symbiotic microbiomes of coral reefs sponges and corals. Springer Netherlands, Dordrecht, The Netherlands.

20. Fiore CL, Labrie M, Jarett JK, Lesser MP. 2015. Transcriptional activity of the giant barrel sponge, Xestospongia muta holobiont: molecular evidence for metabolic interchange. Front Microbiol 6:364. https://doi.org/ 10.3389/fmicb.2015.00364.

21. Fan L, Reynolds D, Liu M, Stark M, Kjelleberg S, Webster NS, Thomas T. 2012. Functional equivalence and evolutionary convergence in complex communities of microbial sponge symbionts. Proc Natl Acad Sci U S A 109:E1878-E1887. https://doi.org/10.1073/pnas.1203287109.

22. Bayer K, Jahn MT, Slaby BM, Moitinho-Silva L, Hentschel U. 2018. Marine sponges as Chloroflexi hot spots: genomic insights and high-resolution visualization of an abundant and diverse symbiotic clade. mSystems 3 : e00150-18. https://doi.org/10.1128/mSystems.00150-18.

23. Karimi E, Keller-Costa T, Slaby BM, Cox CJ, da Rocha UN, Hentschel U, Costa R. 2019. Genomic blueprints of sponge-prokaryote symbiosis are shared by low abundant and cultivatable Alphaproteobacteria. Sci Rep 9: 1999. https://doi.org/10.1038/s41598-019-38737-x.

24. Song H, Hewitt OH, Degnan SM. 2020. Bacterial symbionts in animal development: arginine biosynthesis complementation enables larval settlement in a marine sponge. bioRxiv https://doi.org/10.1101/2020.08.06 .240770 .

25. Helber SB, Hoeijmakers DJJ, Muhando CA, Rohde S, Schupp PJ. 2018. Sponge chemical defenses are a possible mechanism for increasing sponge abundance on reefs in Zanzibar. PLoS One 13:e0197617. https:// doi.org/10.1371/journal.pone.0197617.

26. Lopanik NB. 2014. Chemical defensive symbioses in the marine environment. Funct Ecol 28:328-340. https://doi.org/10.1111/1365-2435.12160.

27. Mori T, Cahn JKB, Wilson MC, Meoded RA, Wiebach V, Martinez AFC, Helfrich EJN, Albersmeier A, Wibberg D, Dätwyler S, Keren R, Lavy A, Rückert C, Ilan M, Kalinowski J, Matsunaga S, Takeyama H, Piel J. 2018. Single-bacterial genomics validates rich and varied specialized metabolism of uncultivated Entotheonella sponge symbionts. Proc Natl Acad Sci U S A 115:1718-1723. https://doi.org/10.1073/pnas.1715496115.

28. Newman DJ, Cragg GM. 2020. Natural products as sources of new drugs over the nearly four decades from 01/1981 to 09/2019. J Nat Prod 83: 770-803. https://doi.org/10.1021/acs.jnatprod.9b01285.

29. Pita L, Hoeppner MP, Ribes M, Hentschel U. 2018. Differential expression of immune receptors in two marine sponges upon exposure to microbial-associated molecular patterns. Sci Rep 8:16081. https://doi.org/10 .1038/s41598-018-34330-w.

30. Degnan SM. 2015. The surprisingly complex immune gene repertoire of a simple sponge, exemplified by the NLR genes: a capacity for specificity? Dev Comp Immunol 48:269-274. https://doi.org/10.1016/j.dci.2014 .07.012. 
31. Reynolds D, Thomas T. 2016. Evolution and function of eukaryotic-like proteins from sponge symbionts. Mol Ecol 25:5242-5253. https://doi .org/10.1111/mec.13812.

32. Thomas T, Moitinho-Silva L, Lurgi M, Björk JR, Easson C, Astudillo-García C, Olson JB, Erwin PM, López-Legentil S, Luter H, Chaves-Fonnegra A, Costa R, Schupp PJ, Steindler L, Erpenbeck D, Gilbert J, Knight R, Ackermann G, Victor Lopez J, Taylor MW, Thacker RW, Montoya JM, Hentschel U, Webster NS. 2016. Diversity, structure and convergent evolution of the global sponge microbiome. Nat Commun 7:11870. https:// doi.org/10.1038/ncomms11870.

33. Astudillo-García C, Slaby BM, Waite DW, Bayer K, Hentschel U, Taylor MW. 2018. Phylogeny and genomics of SAUL, an enigmatic bacterial lineage frequently associated with marine sponges. Environ Microbiol 20: 561-576. https://doi.org/10.1111/1462-2920.13965.

34. Fieseler L, Horn M, Wagner M, Hentschel U. 2004. Discovery of the novel candidate phylum "Poribacteria" in marine sponges. Appl Environ Microbiol 70:3724-3732. https://doi.org/10.1128/AEM.70.6.3724-3732.2004.

35. Tully BJ, Graham ED, Heidelberg JF. 2018. The reconstruction of 2,631 draft metagenome-assembled genomes from the global oceans. Sci Data 5:170203. https://doi.org/10.1038/sdata.2017.203.

36. Podell S, Blanton JM, Neu A, Agarwal V, Biggs JS, Moore BS, Allen EE. 2019. Pangenomic comparison of globally distributed Poribacteria associated with sponge hosts and marine particles. ISME J 13:468-481. https://doi.org/10.1038/s41396-018-0292-9.

37. Lafi FF, Fuerst JA, Fieseler L, Engels C, Goh WWL, Hentschel U. 2009. Widespread distribution of Poribacteria in Demospongiae. Appl Environ Microbiol 75:5695-5699. https://doi.org/10.1128/AEM.00035-09.

38. Steinert G, Gutleben J, Atikana A, Wijffels RH, Smidt H, Sipkema D. 2018. Coexistence of poribacterial phylotypes among geographically widespread and phylogenetically divergent sponge hosts. Environ Microbiol Rep 10:80-91. https://doi.org/10.1111/1758-2229.12609.

39. Siegl A, Kamke J, Hochmuth T, Piel J, Richter M, Liang C, Dandekar T, Hentschel U. 2011. Single-cell genomics reveals the lifestyle of Poribacteria, a candidate phylum symbiotically associated with marine sponges. ISME J 5:61-70. https://doi.org/10.1038/ismej.2010.95.

40. Kamke J, Rinke C, Schwientek P, Mavromatis K, Ivanova N, Sczyrba A, Woyke T, Hentschel U. 2014. The candidate phylum Poribacteria by single-cell genomics: new insights into phylogeny, cell-compartmentation, eukaryote-like repeat proteins, and other genomic features. PLoS One 9: e87353. https://doi.org/10.1371/journal.pone.0087353.

41. Kamke J, Sczyrba A, Ivanova N, Schwientek P, Rinke C, Mavromatis K, Woyke T, Hentschel U. 2013. Single-cell genomics reveals complex carbohydrate degradation patterns in poribacterial symbionts of marine sponges. ISME J 7:2287-2300. https://doi.org/10.1038/ismej.2013.111.

42. Jahn MT, Markert SM, Ryu T, Ravasi T, Stigloher C, Hentschel U, MoitinhoSilva L. 2016. Shedding light on cell compartmentation in the candidate phylum Poribacteria by high resolution visualisation and transcriptional profiling. Sci Rep 6:35860. https://doi.org/10.1038/srep35860.

43. Hill MS, Sacristán-Soriano O. 2017. Molecular and functional ecology of sponges and their microbial symbionts, p 105-142. In Carballo JL, Bell JJ (ed), Climate change, ocean acidification and sponges: impacts across multiple levels of organization. Springer International Publishing, Cham, Switzerland.

44. Chen ML, Becraft ED, Pachiadaki M, Brown JM, Jarett JK, Gasol JM, Ravin NV, Moser DP, Nunoura T, Herndl GJ, Woyke T, Stepanauskas R. 2020. Hiding in plain sight: the globally distributed bacterial candidate Phylum PAUC34f. Front Microbiol 11:376. https://doi.org/10.3389/fmicb .2020 .00376 .

45. Taylor JA, Palladino G, Wemheuer B, Steinert G, Sipkema D, Williams TJ, Thomas T. 2021. Phylogeny resolved, metabolism revealed: functional radiation within a widespread and divergent clade of sponge symbionts. ISME J 15:503-519. https://doi.org/10.1038/s41396-020-00791-z.

46. Cleary DFR, Swierts T, Coelho FJRC, Polónia ARM, Huang YM, Ferreira MRS, Putchakarn S, Carvalheiro L, van der Ent E, Ueng J-P, Gomes NCM, de Voogd NJ. 2019. The sponge microbiome within the greater coral reef microbial metacommunity. Nat Commun 10:1644. https://doi.org/ 10.1038/s41467-019-09537-8.

47. Croué J, West NJ, Escande M-L, Intertaglia L, Lebaron P, Suzuki MT. 2013. A single betaproteobacterium dominates the microbial community of the crambescidine-containing sponge Crambe crambe. Sci Rep 3:2583. https://doi.org/10.1038/srep02583.

48. Thiel V, Neulinger SC, Staufenberger T, Schmaljohann R, Imhoff JF. 2007. Spatial distribution of sponge-associated bacteria in the Mediterranean sponge Tethya aurantium. FEMS Microbiol Ecol 59:47-63. https://doi .org/10.1111/j.1574-6941.2006.00217.x.

49. Waterworth SC, Jiwaji M, Kalinski J-CJ, Parker-Nance S, Dorrington RA. 2017. A place to call home: an analysis of the bacterial communities in two Tethya rubra Samaai and Gibbons 2005 populations in Algoa Bay, South Africa. Mar Drugs 15:95. https://doi.org/10.3390/md15040095.

50. Cárdenas CA, Bell JJ, Davy SK, Hoggard M, Taylor MW. 2014. Influence of environmental variation on symbiotic bacterial communities of two temperate sponges. FEMS Microbiol Ecol 88:516-527. https://doi.org/10 .1111/1574-6941.12317.

51. Steinert G, Taylor MW, Deines P, Simister RL, de Voogd NJ, Hoggard M, Schupp PJ. 2016. In four shallow and mesophotic tropical reef sponges from Guam the microbial community largely depends on host identity. PeerJ 4:e1936. https://doi.org/10.7717/peerj.1936.

52. Webster NS, Wilson KJ, Blackall LL, Hill RT. 2001. Phylogenetic diversity of bacteria associated with the marine sponge Rhopaloeides odorabile. Appl Environ Microbiol 67:434-444. https://doi.org/10.1128/AEM.67.1 .434-444.2001.

53. Cleary DFR, Becking LE, de Voogd NJ, Pires ACC, Polónia ARM, Egas C, Gomes NCM. 2013. Habitat- and host-related variation in sponge bacterial symbiont communities in Indonesian waters. FEMS Microbiol Ecol 85:465-482. https://doi.org/10.1111/1574-6941.12135.

54. Trindade-Silva AE, Rua C, Silva GGZ, Dutilh BE, Moreira APB, Edwards RA, Hajdu E, Lobo-Hajdu G, Vasconcelos AT, Berlinck RGS, Thompson FL. 2012. Taxonomic and functional microbial signatures of the endemic marine sponge Arenosclera brasiliensis. PLoS One 7:e39905. https://doi .org/10.1371/journal.pone.0039905.

55. Fieth RA, Gauthier M-EA, Bayes J, Green KM, Degnan SM. 2016. Ontogenetic changes in the bacterial symbiont community of the tropical Demosponge Amphimedon queenslandica: metamorphosis is a new beginning. Front Mar Sci 3:228. https://doi.org/10.3389/fmars.2016.00228.

56. Matcher GF, Waterworth SC, Walmsley TA, Matsatsa T, Parker-Nance S, Davies-Coleman MT, Dorrington RA. 2017. Keeping it in the family: coevolution of latrunculid sponges and their dominant bacterial symbionts. Microbiologyopen 6:e00417. https://doi.org/10.1002/mbo3.417.

57. Walmsley TA, Matcher GF, Zhang F, Hill RT, Davies-Coleman MT, Dorrington RA. 2012. Diversity of bacterial communities associated with the Indian Ocean sponge Tsitsikamma favus that contains the bioactive pyrroloiminoquinones, tsitsikammamine A and B. Mar Biotechnol (NY) 14:681-691. https://doi.org/10.1007/s10126-012-9430-y.

58. Antunes EM, Copp BR, Davies-Coleman MT, Samaai T. 2005. Pyrroloiminoquinone and related metabolites from marine sponges. Nat Prod Rep 22:62-72. https://doi.org/10.1039/b407299p.

59. Kalinski J-CJ, Krause RWM, Parker-Nance S, Waterworth SC, Dorrington RA. 2021. Unlocking the diversity of pyrroloiminoquinones produced by Latrunculid sponge species. Mar Drugs 19:68. https://doi.org/10.3390/ md19020068.

60. Samaai T, Kelly M, Ngwakum B, Payne R, Teske PR, Janson L, Kerwath S, Parker D, Gibbons MJ. 2020. New Latrunculiidae (Demospongiae, Poecilosclerida) from the Agulhas ecoregion of temperate southern Africa. Zootaxa 4896:zootaxa.4896.3.4. https://doi.org/10.11646/zootaxa.4896.3.4.

61. Parks DH, Chuvochina M, Waite DW, Rinke C, Skarshewski A, Chaumeil PA, Hugenholtz P. 2018. A standardized bacterial taxonomy based on genome phylogeny substantially revises the tree of life. Nat Biotechnol 36: 996-1004. https://doi.org/10.1038/nbt.4229.

62. Bowers RM, Kyrpides NC, Stepanauskas R, Harmon-Smith M, Doud D, Reddy TBK, Schulz F, Jarett J, Rivers AR, Eloe-Fadrosh EA, Tringe SG, Ivanova NN, Copeland A, Clum A, Becraft ED, Malmstrom RR, Birren B, Podar M, Bork P, Weinstock GM, Garrity GM, Dodsworth JA, Yooseph S, Sutton G, Glöckner FO, Gilbert JA, Nelson WC, Hallam SJ, Jungbluth SP, Ettema TJG, Tighe S, Konstantinidis KT, Liu W-T, Baker BJ, Rattei T, Eisen JA, Hedlund B, McMahon KD, Fierer N, Knight R, Finn R, Cochrane G, Karsch-Mizrachi I, Tyson GW, Rinke C, Lapidus A, Meyer F, Yilmaz P, Parks DH, Eren AM, Genome Standards Consortium, et al. 2017. Minimum information about a single amplified genome (MISAG) and a metagenome-assembled genome (MIMAG) of bacteria and archaea. Nat Biotechnol 35:725-731. https://doi.org/10.1038/nbt.3893.

63. McCutcheon JP, Moran NA. 2011. Extreme genome reduction in symbiotic bacteria. Nat Rev Microbiol 10:13-26. https://doi.org/10.1038/ nrmicro2670.

64. Manzano-Marín A, Latorre A. 2016. Snapshots of a shrinking partner: genome reduction in Serratia symbiotica. Sci Rep 6:32590. https://doi.org/ 10.1038/srep32590. 
65. Feng $\mathrm{H}$, Edwards $\mathrm{N}$, Anderson $\mathrm{CMH}$, Althaus $\mathrm{M}$, Duncan RP, Hsu $\mathrm{Y}-\mathrm{C}$, Luetje CW, Price DRG, Wilson ACC, Thwaites DT. 2019. Trading amino acids at the aphid: Buchnera symbiotic interface. Proc Natl Acad Sci U S A 116:16003-16011. https://doi.org/10.1073/pnas.1906223116.

66. Knobloch S, Jóhannsson R, Marteinsson Vñ. 2020. Genome analysis of sponge symbiont "Candidatus Halichondribacter symbioticus" shows genomic adaptation to a host-dependent lifestyle. Environ Microbiol 22: 483-498. https://doi.org/10.1111/1462-2920.14869.

67. Niehaus TD, Elbadawi-Sidhu M, de Crécy-Lagard V, Fiehn O, Hanson AD. 2017. Discovery of a widespread prokaryotic 5-oxoprolinase that was hiding in plain sight. J Biol Chem 292:16360-16367. https://doi.org/10 .1074/jbc.M117.805028.

68. Chen K, Reuter M, Sanghvi B, Roberts GA, Cooper LP, Tilling M, Blakely GW, Dryden DTF. 2014. ArdA proteins from different mobile genetic elements can bind to the EcoKI type I DNA methyltransferase of E. coli K12. Biochim Biophys Acta 1844:505-511. https://doi.org/10.1016/j.bbapap .2013.12.008.

69. Boyd CD, Smith TJ, El-Kirat-Chatel S, Newell PD, Dufrêne YF, O'Toole GA. 2014. Structural features of the Pseudomonas fluorescens biofilm adhesin LapA required for LapG-dependent cleavage, biofilm formation, and cell surface localization. J Bacteriol 196:2775-2788. https://doi.org/10.1128/ JB.01629-14.

70. Al-Khodor S, Price CT, Kalia A, Abu Kwaik Y. 2010. Functional diversity of ankyrin repeats in microbial proteins. Trends Microbiol 18:132-139. https://doi.org/10.1016/j.tim.2009.11.004.

71. Said Hassane C, Fouillaud M, Le Goff G, Sklirou AD, Boyer JB, Trougakos IP, Jerabek M, Bignon J, de Voogd NJ, Ouazzani J, Gauvin-Bialecki A, Dufossé L. 2020. Microorganisms associated with the marine sponge Scopalina hapalia: a reservoir of bioactive molecules to slow down the aging process. Microorganisms 8:1262. https://doi.org/10.3390/microorganisms8091262.

72. Konstantinidis KT, Rosselló-Móra R, Amann R. 2017. Uncultivated microbes in need of their own taxonomy. ISME J 11:2399-2406. https:// doi.org/10.1038/ismej.2017.113.

73. Murray $A E$, Freudenstein J, Gribaldo S, Hatzenpichler R, Hugenholtz $P$, Kämpfer $\mathrm{P}$, Konstantinidis KT, Lane CE, Papke RT, Parks DH, RosselloMora R, Stott MB, Sutcliffe IC, Thrash JC, Venter SN, Whitman WB, Acinas SG, Amann RI, Anantharaman K, Armengaud J, Baker BJ, Barco RA, Bode HB, Boyd ES, Brady CL, Carini P, Chain PSG, Colman DR, DeAngelis KM, de Los Rios MA, Estrada-de Los Santos P, Dunlap CA, Eisen JA, Emerson D, Ettema TJG, Eveillard D, Girguis PR, Hentschel U, Hollibaugh JT, Hug LA, Inskeep WP, Ivanova EP, Klenk H-P, Li W-J, Lloyd KG, Löffler FE, Makhalanyane TP, Moser DP, Nunoura T, Palmer M, Parro V, et al. 2021. Author correction: roadmap for naming uncultivated Archaea and Bacteria. Nat Microbiol 6:136. https://doi.org/10.1038/s41564-020-00827-2.

74. Murray $A E$, Freudenstein J, Gribaldo $S$, Hatzenpichler R, Hugenholtz $P$, Kämpfer $\mathrm{P}$, Konstantinidis KT, Lane CE, Papke RT, Parks DH, RosselloMora R, Stott MB, Sutcliffe IC, Thrash JC, Venter SN, Whitman WB, Acinas SG, Amann RI, Anantharaman K, Armengaud J, Baker BJ, Barco RA, Bode $\mathrm{HB}$, Boyd ES, Brady CL, Carini P, Chain PSG, Colman DR, DeAngelis KM, de Los Rios MA, Estrada-de Los Santos P, Dunlap CA, Eisen JA, Emerson D, Ettema TJG, Eveillard D, Girguis PR, Hentschel U, Hollibaugh JT, Hug LA, Inskeep WP, Ivanova EP, Klenk H-P, Li W-J, Lloyd KG, Löffler FE, Makhalanyane TP, Moser DP, Nunoura T, Palmer M, Parro V, et al. 2020. Roadmap for naming uncultivated Archaea and Bacteria. Nat Microbiol 5:987-994. https://doi.org/10.1038/s41564-020-0733-x.

75. Chuvochina M, Rinke C, Parks DH, Rappé MS, Tyson GW, Yilmaz $P$, Whitman WB, Hugenholtz P. 2019. The importance of designating type material for uncultured taxa. Syst Appl Microbiol 42:15-21. https://doi .org/10.1016/j.syapm.2018.07.003.

76. Pallen MJ, Telatin A, Oren A. 2021. The next million names for Archaea and Bacteria. Trends Microbiol 29:289-298. https://doi.org/10.1016/j.tim 2020.10.009.

77. Munroe S, Sandoval K, Martens DE, Sipkema D, Pomponi SA. 2019. Genetic algorithm as an optimization tool for the development of sponge cell culture media. In Vitro Cell Dev Biol Anim 55:149-158. https://doi.org/10 .1007/s11626-018-00317-0.

78. Voth W, Jakob U. 2017. Stress-activated chaperones: a first line of defense. Trends Biochem Sci 42:899-913. https://doi.org/10.1016/j.tibs .2017.08.006

79. Gottesman S, Wickner S, Maurizi MR. 1997. Protein quality control: triage by chaperones and proteases. Genes Dev 11:815-823. https://doi.org/10 .1101/gad.11.7.815.

80. Cohn MT, Ingmer H, Mulholland F, Jørgensen K, Wells JM, Brøndsted L. 2007. Contribution of conserved ATP-dependent proteases of
Campylobacter jejuni to stress tolerance and virulence. Appl Environ Microbiol 73:7803-7813. https://doi.org/10.1128/AEM.00698-07.

81. Thomsen LE, Olsen JE, Foster JW, Ingmer H. 2002. ClpP is involved in the stress response and degradation of misfolded proteins in Salmonella enterica serovar Typhimurium. Microbiology (Reading) 148:2727-2733. https://doi.org/10.1099/00221287-148-9-2727.

82. Gennaris A, Ezraty B, Henry C, Agrebi R, Vergnes A, Oheix E, Bos J, Leverrier P, Espinosa L, Szewczyk J, Vertommen D, Iranzo O, Collet J-F, Barras F. 2015. Repairing oxidized proteins in the bacterial envelope using respiratory chain electrons. Nature 528:409-412. https://doi.org/ 10.1038/nature15764.

83. Lavy A, Keren R, Yahel G, Ilan M. 2016. Intermittent hypoxia and prolonged suboxia measured in situ in a marine sponge. Front Mar Sci 3: 263. https://doi.org/10.3389/fmars.2016.00263.

84. Fan L, Liu M, Simister R, Webster NS, Thomas T. 2013. Marine microbial symbiosis heats up: the phylogenetic and functional response of a sponge holobiont to thermal stress. ISME J 7:991-1002. https://doi.org/ 10.1038/ismej.2012.165.

85. Simister R, Taylor MW, Tsai P, Fan L, Bruxner TJ, Crowe ML, Webster N. 2012. Thermal stress responses in the bacterial biosphere of the Great Barrier Reef sponge, Rhopaloeides odorabile. Environ Microbiol 14: 3232-3246. https://doi.org/10.1111/1462-2920.12010.

86. Guzman C, Conaco C. 2016. Gene expression dynamics accompanying the sponge thermal stress response. PLoS One 11:e0165368. https://do .org/10.1371/journal.pone.0165368.

87. Tziveleka L-A, loannou E, Tsiourvas D, Berillis P, Foufa E, Roussis V. 2017. Collagen from the marine sponges Axinella cannabina and Suberites carnosus: isolation and morphological, biochemical, and biophysical characterization. Mar Drugs 15:152. https://doi.org/10.3390/md15060152.

88. Hanson BT, Hewson I, Madsen EL. 2014. Metaproteomic survey of six aquatic habitats: discovering the identities of microbial populations active in biogeochemical cycling. Microb Ecol 67:520-539. https://doi org/10.1007/s00248-013-0346-5.

89. Shih JL, Selph KE, Wall CB, Wallsgrove NJ, Lesser MP, Popp BN. 2020. Trophic ecology of the tropical Pacific sponge Mycale grandis inferred from amino acid compound-specific isotopic analyses. Microb Ecol 79: 495-510. https://doi.org/10.1007/s00248-019-01410-x.

90. Hosie AHF, Allaway D, Galloway CS, Dunsby HA, Poole PS. 2002. Rhizobium leguminosarum has a second general amino acid permease with unusually broad substrate specificity and high similarity to branchedchain amino acid transporters (Bra/LIV) of the ABC family. J Bacteriol 184: 4071-4080. https://doi.org/10.1128/JB.184.15.4071-4080.2002.

91. Prell J, White JP, Bourdes A, Bunnewell S, Bongaerts RJ, Poole PS. 2009. Legumes regulate Rhizobium bacteroid development and persistence by the supply of branched-chain amino acids. Proc Natl Acad Sci U S A 106: 12477-12482. https://doi.org/10.1073/pnas.0903653106.

92. Hogle SL, Barbeau KA, Gledhill M. 2014. Heme in the marine environment: from cells to the iron cycle. Metallomics 6:1107-1120. https://do .org/10.1039/c4mt00031e.

93. Ekman M, Picossi S, Campbell EL, Meeks JC, Flores E. 2013. A Nostoc punctiforme sugar transporter necessary to establish a Cyanobacteriumplant symbiosis. Plant Physiol 161:1984-1992. https://doi.org/10.1104/ pp.112.213116.

94. Neave MJ, Michell CT, Apprill A, Voolstra CR. 2017. Endozoicomonas genomes reveal functional adaptation and plasticity in bacterial strains symbiotically associated with diverse marine hosts. Sci Rep 7:40579. https://doi.org/10.1038/srep40579.

95. Rix L, Ribes M, Coma R, Jahn MT, de Goeij JM, van Oevelen D, Escrig S Meibom A, Hentschel U. 2020. Heterotrophy in the earliest gut: a singlecell view of heterotrophic carbon and nitrogen assimilation in spongemicrobe symbioses. ISME J 14:2554-2567. https://doi.org/10.1038/s41396 -020-0706-3.

96. Erwin PM, Coma R, López-Sendino P, Serrano E, Ribes M. 2015. Stable symbionts across the HMA-LMA dichotomy: low seasonal and interannual variation in sponge-associated bacteria from taxonomically diverse hosts. FEMS Microbiol Ecol 91:fiv115. https://doi.org/10.1093/femsec/ fiv 115.

97. Moitinho-Silva L, Steinert G, Nielsen S, Hardoim CCP, Wu Y-C, McCormack GP, López-Legentil S, Marchant R, Webster N, Thomas T, Hentschel U. 2017. Predicting the HMA-LMA status in marine sponges by machine learning. Front Microbiol 8:752. https://doi.org/10.3389/fmicb.2017.00752.

98. Lurgi M, Thomas T, Wemheuer B, Webster NS, Montoya JM. 2019. Modularity and predicted functions of the global sponge-microbiome network. Nat Commun 10:992. https://doi.org/10.1038/s41467-019-08925-4. 
99. Bayer K, Moitinho-Silva L, Brümmer F, Cannistraci CV, Ravasi T, Hentschel U. 2014. GeoChip-based insights into the microbial functional gene repertoire of marine sponges (high microbial abundance, low microbial abundance) and seawater. FEMS Microbiol Ecol 90:832-843. https://doi .org/10.1111/1574-6941.12441.

100. Rubin-Blum M, Antony CP, Sayavedra L, Martínez-Pérez C, Birgel D, Peckmann J, Wu Y-C, Cardenas P, MacDonald I, Marcon Y, Sahling H, Hentschel U, Dubilier N. 2019. Fueled by methane: deep-sea sponges from asphalt seeps gain their nutrition from methane-oxidizing symbionts. ISME J 13:1209-1225. https://doi.org/10.1038/s41396-019-0346-7.

101. Silva FJ, Santos-Garcia D. 2015. Slow and fast evolving endosymbiont lineages: positive correlation between the rates of synonymous and non-synonymous substitution. Front Microbiol 6:1279. https://doi.org/ 10.3389/fmicb.2015.01279.

102. Wu S, Ou H, Liu T, Wang D, Zhao J. 2018. Structure and dynamics of microbiomes associated with the marine sponge Tedania sp. during its life cycle. FEMS Microbiol Ecol 94:fiy055. https://doi.org/10.1093/femsec/fiy055.

103. Samaai T, Kelly M. 2002. Family Latrunculiidae Topsent, 1922, p 708-719. In Hooper JNA, Van Soest RWM, Willenz P (ed), Systema Porifera: a guide to the classification of sponges. Springer US, Boston, MA.

104. Parker-Nance S, Hilliar S, Waterworth S, Walmsley T, Dorrington R. 2019. New species in the sponge genus Tsitsikamma (Poecilosclerida, Latrunculiidae) from South Africa. Zookeys 874:101-126. https://doi.org/10.3897/ zookeys.874.32268.

105. Hamlyn-Harris R. 1996. Memoirs of the Queensland Museum, vol 40. Queensland Museum, Brisbane, Australia.

106. Bankevich A, Nurk S, Antipov D, Gurevich AA, Dvorkin M, Kulikov AS, Lesin VM, Nikolenko SI, Pham S, Prjibelski AD, Pyshkin AV, Sirotkin AV, Vyahhi N, Tesler G, Alekseyev MA, Pevzner PA. 2012. SPAdes: a new genome assembly algorithm and its applications to single-cell sequencing. J Comput Biol 19:455-477. https://doi.org/10.1089/cmb.2012.0021.

107. Miller IJ, Rees ER, Ross J, Miller I, Baxa J, Lopera J, Kerby RL, Rey FE, Kwan JC. 2019. Autometa: automated extraction of microbial genomes from individual shotgun metagenomes. Nucleic Acids Res 47:e57. https://doi .org/10.1093/nar/gkz148.

108. Parks DH, Imelfort M, Skennerton CT, Hugenholtz P, Tyson GW. 2015. CheckM: assessing the quality of microbial genomes recovered from isolates, single cells, and metagenomes. Genome Res 25:1043-1055. https:// doi.org/10.1101/gr.186072.114.

109. Bolger AM, Lohse M, Usadel B. 2014. Trimmomatic: a flexible trimmer for Illumina sequence data. Bioinformatics 30:2114-2120. https://doi.org/10 .1093/bioinformatics/btu170.

110. Chaumeil P-A, Mussig AJ, Hugenholtz P, Parks DH. 2019. GTDB-Tk: a toolkit to classify genomes with the Genome Taxonomy Database. Bioinformatics 36:1925-1927. https://doi.org/10.1093/bioinformatics/btz848.

111. Johnson M, Zaretskaya I, Raytselis Y, Merezhuk Y, McGinnis S, Madden TL. 2008. NCBI BLAST: a better Web interface. Nucleic Acids Res 36:W5-W9. https://doi.org/10.1093/nar/gkn201.
112. Alanjary M, Steinke K, Ziemert N. 2019. AutoMLST: an automated Web server for generating multi-locus species trees highlighting natura product potential. Nucleic Acids Res 47:W276-W282. https://doi.org/10 .1093/nar/gkz282.

113. Seemann T. 2014. Prokka: rapid prokaryotic genome annotation. Bioinformatics 30:2068-2069. https://doi.org/10.1093/bioinformatics/btu153.

114. Aramaki T, Blanc-Mathieu R, Endo H, Ohkubo K, Kanehisa M, Goto S, Ogata H. 2020. KofamKOALA: KEGG ortholog assignment based on profile HMM and adaptive score threshold. Bioinformatics 36:2251-2252. https://doi.org/10.1093/bioinformatics/btz859.

115. Blin K, Shaw S, Steinke K, Villebro R, Ziemert N, Lee SY, Medema MH, Weber T. 2019. antiSMASH 5.0: updates to the secondary metabolite genome mining pipeline. Nucleic Acids Res 47:W81-W87. https://doi.org/ 10.1093/nar/gkz310.

116. Rodriguez-R LM, Konstantinidis KT. 2016. The enveomics collection: a toolbox for specialized analyses of microbial genomes and metagenomes. PeerJ Preprints 4:e1900v1. https://doi.org/10.7287/peerj.preprints.1900v1.

117. Dixon P. 2003. VEGAN, a package of R functions for community ecology. J Veg Sci 14:927-930. https://doi.org/10.1111/j.1654-1103.2003.tb02228.x.

118. Waterworth SC, Flórez LV, Rees ER, Hertweck C, Kaltenpoth M, Kwan JC 2020. Horizontal gene transfer to a defensive symbiont with a reduced genome in a multipartite beetle microbiome. mBio 11:e02430-19. https://doi .org/10.1128/mBio.02430-19.

119. Altenhoff AM, Levy J, Zarowiecki M, Tomiczek B, Warwick Vesztrocy A Dalquen DA, Müller S, Telford MJ, Glover NM, Dylus D, Dessimoz C. 2019. OMA standalone: orthology inference among public and custom genomes and transcriptomes. Genome Res 29:1152-1163. https://do .org/10.1101/gr.243212.118.

120. Edgar RC. 2004. MUSCLE: multiple sequence alignment with high accuracy and high throughput. Nucleic Acids Res 32:1792-1797. https://doi .org/10.1093/nar/gkh340.

121. Rice P, Longden I, Bleasby A. 2000. EMBOSS: the European Molecular Biology Open Software Suite. Trends Genet 16:276-277. https://doi.org/ 10.1016/s0168-9525(00)02024-2.

122. Suyama M, Torrents D, Bork P. 2006. PAL2NAL: robust conversion of protein sequence alignments into the corresponding codon alignments. Nucleic Acids Res 34:W609-W612. https://doi.org/10.1093/nar/gkl315.

123. Kumar S, Stecher G, Li M, Knyaz C, Tamura K. 2018. MEGA X: Molecular Evolutionary Genetics Analysis across computing platforms. Mol Bio Evol 35:1547-1549. https://doi.org/10.1093/molbev/msy096.

124. Schlee D, Sneath PHA, Sokal RR, Freeman WH. 1975. Numerical taxonomy. The principles and practice of numerical classification. Syst Zool 24:263-268. https://doi.org/10.2307/2412767.

125. Buchfink B, Xie C, Huson DH. 2015. Fast and sensitive protein alignment using DIAMOND. Nat Methods 12:59-60. https://doi.org/10.1038/nmeth.3176. 